\title{
Development of conventional dendritic cells: from common bone marrow progenitors to multiple subsets in peripheral tissues
}

\author{
D Sichien ${ }^{1,2}$, BN Lambrecht ${ }^{1,3,4}, \mathrm{M}$ Guilliams ${ }^{1,2}$ and CL Scott ${ }^{1,2}$
}

Our understanding of conventional dendritic cell (cDC) development and the functional specializations of distinct subsets in the peripheral tissues has increased greatly in recent years. Here, we review CDC development from the distinct progenitors in the bone marrow through to the distinct CDC subsets found in barrier tissues, providing an overview of the different subsets described in each location. In addition, we detail the transcription factors and local signals that have been proposed to control this developmental process. Importantly, despite these significant advances, numerous questions remain to be answered regarding $\mathrm{CDC}$ development. For example, it remains unclear whether the different subsets described, such as the $\mathrm{CD} 103^{+} \mathrm{CD} 11 \mathrm{~b}^{+}$and $\mathrm{CD} 103^{-} \mathrm{CD} 11 \mathrm{~b}^{+} \mathrm{cDC}$ in the intestines, truly represent different populations or rather distinct developmental or activation stages. Furthermore, whether distinct progenitors exist for these $\mathrm{CDC}$ subsets remains to be determined. Thus in the last part of this review we discuss what we believe will be the main questions facing the field for the coming years.

\section{INTRODUCTION}

Dendritic cells (DCs) were first described by Steinman and Cohn. ${ }^{1}$ They are present in almost every tissue of the body where they form the crucial link between the innate and adaptive immune systems. DCs can be subdivided into three main groups, namely the conventional DCs (cDCs), the plasmacytoid DCs (pDCs), and the monocyte-derived DCs (moDCs). moDCs are the most controversial of the three populations. However, given their use in many human-based cancer immunotherapies ${ }^{2}$ they cannot be excluded from discussion. They are routinely generated in vitro following culture of monocytes from both human and mouse with granulocyte-macrophage colony stimulating factor (GM-CSF, CSF-2) and interleukin4 (IL4). ${ }^{3,4}$ However their presence in vivo remains disputed ${ }^{5,6}$ (see below). pDCs are specialized in the production of type I interferons during viral infections and are critical in antiviral immune responses. ${ }^{7} \mathrm{cDCs}$ are the professional antigen-presenting cells of the innate immune system $^{8}$ and hence will be the focus of this review. In the tissues, they patrol the local environment and sample antigens. Upon sampling antigens, cDCs migrate to the T-cell zones of the draining lymph nodes (LNs) in a CCR7-dependent manner. There they present the antigenic peptides to naive $\mathrm{T}$ lymphocytes, inducing their proliferation and polarization into antigen-specific effector or regulatory $\mathrm{T}$ cells, depending upon the additional signals they receive from the cDCs. The activated $\mathrm{T}$ lymphocytes subsequently home to the tissue of the $\mathrm{CDC}$ origin and orchestrate the immune response through production of a collection of immunomodulatory cytokines including IL17, IFN $\gamma$, IL4, IL5, and IL10. ${ }^{8,9}$

The importance of $\mathrm{cDCs}$ in the initiation of appropriate immune responses was highlighted in 2011 when the late Ralph Steinman was awarded the Nobel Prize for his discovery. Thus in recent years, with the advent of multiparameter flow cytometry, CyTOF technology, and RNA sequencing, considerable effort has been focused on the accurate identification and characterization of cDCs. In the past, expression of CD11c and major histocompatibility complex class II (MHCII) has been extensively used to define cDCs. However, with the advent of these new techniques it has become evident that these

${ }^{1}$ Laboratory of Immunoregulation and Mucosal Immunology, VIB-UGent Center for Inflammation Research, Ghent, Belgium. ${ }^{2}$ Department of Biomedical Molecular Biology, Ghent University, Ghent, Belgium. ${ }^{3}$ Department of Respiratory Medicine, Ghent University, Ghent, Belgium and ${ }^{4}$ Department of Pulmonary Medicine, ErasmusMC, Rotterdam, The Netherlands. Correspondence: CL Scott (charlotte.scott@irc.vib-ugent.be) 
markers alone are not sufficient for the precise identification of cDCs. For example, macrophages $(\mathrm{M} \phi s)$, including those in the intestine, ${ }^{10-12}$ liver, ${ }^{13,14}$ and lung interstitium ${ }^{15}$ express both CD11c and MHCII, while those in the lung alveoli ${ }^{16}$ express $\mathrm{CD} 11 \mathrm{c}$ and those in the heart ${ }^{17,18}$ express MHCII. In addition, $\mathrm{T}$ cells, natural killer cells, and plasma cells can also express CD11c. ${ }^{19,20}$ Of note, this widespread expression of CD11c also has knock-on effects for the use of CD11c-driven mouse models including CD11c-CRE and CD11c-DTR mice, as unlike often assumed, these do not specifically target cDCs. Rather they target cDCs alongside the other CD11c-expressing cells described above. The recent identification of the DC-specific transcription factor (TF) Zbtb46 (zDC), which is expressed by $\mathrm{cDCs}$ and in vitro grown moDCs but absent from pDCs and M $\phi s$ although it is expressed on endothelial and erythroid progenitors, ${ }^{6,21-23}$ allows the identification of $\mathrm{CDCs}$ and moDCs within $\mathrm{CD} 45^{+}$cells and will allow the generation of valuable tools for specifically studying DC function, including the $\mathrm{zDC}-\mathrm{DTR} \mathrm{R}^{22}$ and the more recently described zDC-CRE ${ }^{24}$ mice. In addition, transcriptional analysis of distinct $\mathrm{CDC}$ and monocyte/M $\phi$ populations has further aided our ability to specifically identify cDCs. These studies identified "molecular signatures" for $\mathrm{cDCs}$ and $\mathrm{M} \phi \mathrm{s}$ and as a result identified CD26 to be a cDC-specific marker, ${ }^{25}$ and CD64, $\mathrm{CD} 14$, and MerTK as monocyte-/M $\phi$-specific markers. ${ }^{26-28}$ Moreover, the identification of Mafb as a monocyte-/M $\phi$ specific TF further aids the distinction between cells of the monocyte/M $\phi$ lineage and cDCs. ${ }^{6}$ The use of these markers has significantly improved our understanding of the distinct $\mathrm{CDC}$ subsets present in different tissues in recent years. Here, we review the recent advances in our understanding of $\mathrm{cDC}$ ontogeny and focus on the complete developmental pathway of cDCs from common bone marrow (BM) precursors to the distinct $\mathrm{CDC}$ subsets present in barrier tissues.

\section{CONVENTIONAL DENDRITIC CELLS}

cDCs have been historically subdivided into many subsets. The exact number of subsets in each tissue is largely dependent on the "standard" practice for that tissue. ${ }^{29}$ In the murine spleen it is common to use CD 4 and $\mathrm{CD} 8 \alpha$ to define $\mathrm{CDC}$ subsets, which results in three subsets $\left(\mathrm{CD} 8 \alpha^{+} \mathrm{CD} 4^{-}, \mathrm{CD} 8 \alpha^{-} \mathrm{CD} 4^{+}\right.$, and $\mathrm{CD} 8 \alpha^{-} \mathrm{CD} 4^{-}$), however, if $\mathrm{CD} 103$ and $\mathrm{CD} 11 \mathrm{~b}$ would be used to analyze spleen cDCs, as is common practice in the gut, then two or three subsets are found depending of the health status of the animal house $\left(\mathrm{CD}_{103}{ }^{-} \mathrm{CD}_{11} \mathrm{~b}^{+}\right.$and $\mathrm{CD} 103^{-} \mathrm{CD} 11 \mathrm{~b}^{-}$, but also $\mathrm{CD}_{103}{ }^{+} \mathrm{CD} 11 \mathrm{~b}^{-} \mathrm{CDCs}$ in some animal houses) (unpublished data). This has led to considerable confusion in the field regarding how one $\mathrm{CDC}$ subset in one tissue would relate to another subset in a distinct location. To attempt to combat this confusion, it was recently proposed to first group cDCs into two main subsets termed cDC1s and cDC2s. ${ }^{5,30}$ This division is on the basis of their ontogeny, specifically their dependence on the TFs Batf3, Irf8, and Irf4, with cDC1s depending upon Batf3 and Irf8 for their generation and survival $^{31-34}$ and $\mathrm{CDC} 2$ s expressing, and some depending upon Irf4 for their terminal differentiation and survival ${ }^{35,36}$ and/or migration to the draining LNs. ${ }^{37,38}$ In addition, these two subsets can also be distinguished as XCR $1{ }^{+} \mathrm{Cadm}{ }^{+} \mathrm{CD} 172 \mathrm{a}^{-} \mathrm{cDC} 1 \mathrm{~s}$ and $\mathrm{XCR} 1^{-} \mathrm{Cadm}^{-} \mathrm{CD} 172 \mathrm{a}^{+}$cDC2s across tissues and species. ${ }^{12,30,39-43}$ Once the CDCs have been grouped into CDC1s and $\mathrm{CDC} 2 \mathrm{~s}$, respectively, it was proposed to then further subdivide them on the basis of the other unique markers that the populations expressed. Thus for the spleen you could have, for example, $\mathrm{CD} 8 \alpha^{+} \mathrm{cDC1}$ s or endothelial cell specific adhesion marker (ESAM) ${ }^{+}$cDC2s. ${ }^{44}$ This division of cDCs into $\mathrm{cDC} 1 \mathrm{~s}$ and $\mathrm{CDC} 2 \mathrm{~s}$ is also functionally relevant, as $\mathrm{CDC} 1 \mathrm{~s}$ are specialized in cross presentation of antigen to naive $\mathrm{CD} 8^{+} \mathrm{T}$ cells in an MHCI context, ${ }^{31,39,40,45,46}$ whereas cDC2s excel at the presentation of antigen to naive $\mathrm{CD} 4^{+} \mathrm{T}$ cells in an MHCII context, inducing either helper $T$ cells $\left(T_{H}\right)$ or regulatory $T$ cells $\left(T_{R e g}\right){ }^{8}$ As discussed below, it is less clear whether further subdivisions of $\mathrm{cDC1} 1 \mathrm{~s}$ and $\mathrm{cDC} 2 \mathrm{~s}$ into multiple subsets always reflects functional heterogeneity of these cells within tissues or whether in some cases they represent developmental intermediates.

\section{ONTOGENY OF cDCs}

\section{Classical model of CDC development}

In mice, cDCs develop in the BM in a stepwise manner from quiescent long-term self-renewing hematopoietic stem cells in a process called hematopoiesis (Figure 1). Long-term selfrenewing hematopoietic stem cells (HSCs) then differentiate into short-term HSCs and multipotent progenitors. These multipotent progenitors differentiate further into common myeloid progenitors and common lymphoid progenitors (CLP), ${ }^{47-49}$ the first important bifurcation between cells of the myeloid and lymphoid lineages. Common myeloid progenitors then develop into granulocyte macrophage progenitors (GMPs), and macrophage and DC precursors (MDPs), ${ }^{8,50-52}$ Once at the MDP stage, these cells were thought to have lost the potential to generate granulocytes ${ }^{51,53}$ instead differentiating further into common monocyte progenitors $(\mathrm{cMoP})^{53}$ and common DC precursors (CDPs). ${ }^{54-56}$ However, more recently some granulocytic potential of these progenitors has also been described. ${ }^{57}$ Furthermore, this study demonstrated that, contrary to previous reports, the MDP had limited potential to generate cDCs and pDCs, and that the bipotency of the MDP was relatively low, with few MDPs in single-cell assays giving rise to both $\mathrm{m} \phi \mathrm{s}$ and DCs. ${ }^{57,58}$ Although this questions the presence of the MDP as an intermediate step in monocyte/M $\phi$ s and $\mathrm{CDC}$ development, there is no debate that the $\mathrm{cMoP}$ gives rise exclusively to monocytes/mos. While the $\mathrm{cMoP}$ develops into monocytes, ${ }^{53}$ the CDP is thought to generate pre-cDCs and prepDCs, of which the latter develops into pDCs. ${ }^{54-56,59}$ Monocytes, pDCs, and pre-cDCs then leave the BM and seed several lymphoid and non-lymphoid tissues. ${ }^{60,61}$ In these tissues, the pre-cDCs will differentiate further into $\mathrm{cDC} 1 \mathrm{~s}$ and $\mathrm{cDC} 2 \mathrm{~s}$ (Figure 1). Although the origin of $\mathrm{cDCs}$ from myeloid progenitors (CMPs) is widely accepted, it has previously been suggested that cDCs could also develop from lymphoid progenitors (CLPs). ${ }^{47,49}$ However, the contribution of the CLPs to the $\mathrm{CDC}$ populations remains unclear. 


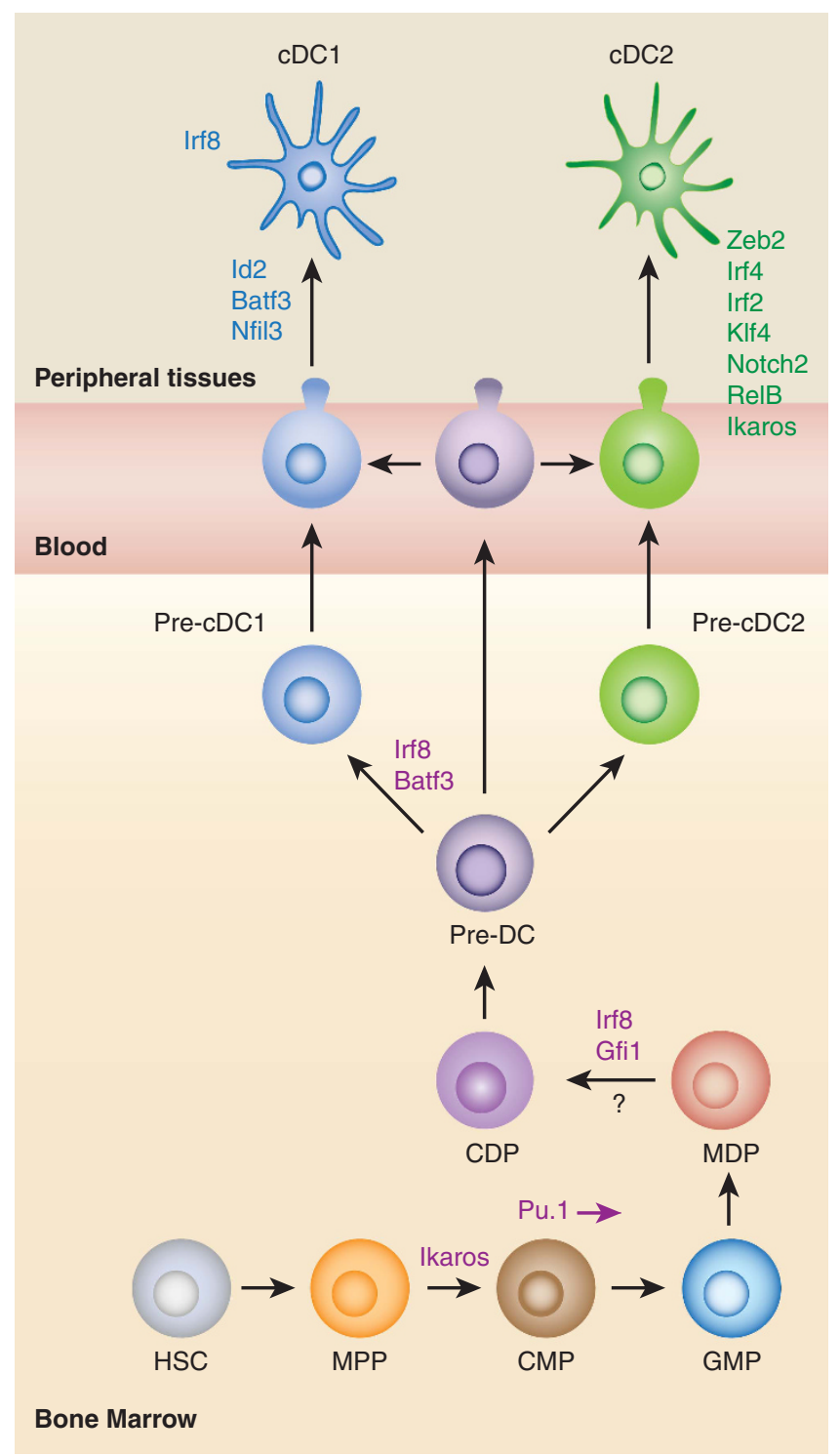

Figure 1 Classical model for $\mathrm{CDC}$ development. $\mathrm{CDCs}$ develop from $\mathrm{BM}$ HSCs in a stepwise manner. HSCs generate MPPs, which then generate CMPs, a step regulated by the TF Ikaros. From this stage on CDC development is regulated at least in part by the TF Pu.1. CMPs then develop into GMPs, which in turn develop into MDPs and CDPs, a step requiring Irf8 and Gfil3, before becoming pre-cDCs. Most BM pre-cDCs are still uncommitted, but these cells gradually split up into Irf8-/Batf3dependent $\mathrm{CDC} 1$-committed pre-cDCs and $\mathrm{CDC2}$-committed pre-cDCs. These pre-cDCs then leave the BM into the bloodstream and seed the different tissues where they differentiate into $\mathrm{CDC} 1 \mathrm{~s}$ or CDC2s. The development of $\mathrm{cDC} 1 \mathrm{~s}$ is dependent upon the TFs Irf8, Id2, Batf3, and $\mathrm{Nfil}$, whereas cDC2s require Zeb2, IIf4, RelB, Notch2, KIf4, IIf2, and Ikaros to varying degrees. BM HSCs, bone marrow hematopoietic stem cells; cDC, conventional dendritic cell; CDP, common DC precursors; CMPs, common myeloid progenitors; GMPs, granulocyte macrophage progenitors; MDP, macrophage and DC precursors; MPPs, multipotent progenitors; TF, transcription factor.

Recent advances in single-cell analysis techniques have resulted in the need to update this model. As a result of work from various research groups, it is now clear that there is considerable heterogeneity among each of these development stages. Perhaps the best example of this is evident at the
pre-cDC stage. Initial studies analyzing CD24 expression on the surface of the splenic pre-cDC population demonstrated that $\mathrm{CD} 24^{\text {hi }}$ and $\mathrm{CD} 24^{\text {lo }}$ cells preferentially generated $\mathrm{cDC} 1 \mathrm{~s}$ and cDC2s, respectively, whereas $\mathrm{CD} 24^{\text {int }}$ cells maintained the potential to generate both subsets. ${ }^{54,61}$ Recently, two studies investigated the heterogeneity within the pre-cDC population into more detail and further defined "pre-cDC1s" committed to cDC1 development, and "pre-cDC2s" committed to cDC2 development both in the BM and the spleen (Figure 1). ${ }^{32,62}$ However, the heterogeneity is not restricted to the pre-cDC stage. Other studies have described heterogeneity in DC progenitor populations much earlier along the developmental continuum. Single-cell transcriptional analysis has revealed there to be $\mathrm{CDC}$ subset-committed precursors present already within the CDP population. ${ }^{62}$ While barcoding of lymphoidprimed multipotent progenitors has demonstrated that DCcommitted progenitors are present even before the bifurcation of the myeloid and lymphoid lineage. ${ }^{63}$ Taken together these findings suggest a model where progenitors can be programmed to become $\mathrm{cDC} 1 \mathrm{~s}$ or $\mathrm{CDC} 2 \mathrm{~s}$ at several steps during their development from HSCs.

Although less extensively studied, a parallel developmental pathway was described to also exist in humans. Recently, two papers were published, which describe the sequential origin of human DCs from increasingly restricted progenitors: a human granulocyte-monocyte-DC progenitor that develops into a human monocyte-dendritic progenitor, which in turn develops into monocytes, and a human CDP that is restricted to generate human pDCs (hpDCs) and human pre-cDCs (hpre-cDCs). These hpre-cDCs were shown to be the immediate precursors of the two cDC subsets. ${ }^{64,65}$ It remains to be fully investigated if the heterogeneity within early DC progenitors also exist in humans. Some early evidence suggests that this could indeed be the case, as limiting dilution assays demonstrated that a proportion of single hpre-cDCs produced just one of the two $\mathrm{CDC}$ subsets, suggesting that a fraction of the hpre-cDCs are already committed to become $\mathrm{CDC} 1$ or $\mathrm{cDC} 2$, similar to mice. ${ }^{64}$

\section{Cytokines regulating $\mathrm{cDC}$ development}

Development and homeostasis of cDCs is in part regulated by the environment through cytokines. The main cytokine regulating DC development is Fms-like tyrosine kinase 3 ligand (Flt3L), which is produced by multiple stromal cells, endothelial cells, and activated T cells. ${ }^{66}$ Downstream signaling upon binding of Flt3L to its receptor Flt3 (CD135) is mediated by STAT3- and PI3K-dependent activation of the mTOR pathway. ${ }^{67,68}$ Culturing BM in the presence of Flt3L generates cells that closely resemble the three main subtypes of DCs found in steady-state conditions (pDCs, cDC1s, and cDC2s). ${ }^{61}$ In addition, increased levels of Flt3L in vivo resulted in significant expansion of DCs. ${ }^{69}$ On the other hand, mice lacking Flt3L, or its receptor Flt3 display profound deficits in all DC populations. ${ }^{34,52,70}$ However, it is notable that $\mathrm{cDC} 1 \mathrm{~s}$ often are more affected by increased/decreased Flt3L levels. ${ }^{12,71}$ The importance of Flt3L signaling in DC development is evident from the 
finding that only BM precursors expressing Flt3 can develop into DCs. ${ }^{59}$ Moreover, enforced Flt3 signaling in Flt3-negative progenitors can drive these cells towards differentiation into pDCs and cDCs, demonstrating that Flt3 signaling is not only necessary but also sufficient for the differentiation of early progenitor populations into DCs. ${ }^{72}$

Although Flt3L plays a continuous role during DC development, other cytokines have also been reported to be involved in a tissue-dependent and/or subset-dependent manner. For example, CSF-2 (GM-CSF) was described to be important for the survival of non-lymphoid tissue-resident $\mathrm{cDC} \mathrm{s}^{73,74}$ and $\mathrm{CD}_{103}{ }^{+}$cDC2s in the intestine. ${ }^{73,75}$ In contrast, others suggested that CSF-2 simply induces the expression of CD103 on cDC1s. ${ }^{76}$ Contrary to CSF-2, lymphotoxin $\alpha 1 \beta 2$ is partially required to maintain splenic $\mathrm{cDC} 2 \mathrm{~s}$ via local homeostatic expansion. ${ }^{77}$ Finally, studies have shown that CSF1 (M-CSF), the main cytokine involved in the development of the monocyte/m $\phi$ lineage, can also drive development of pDCs and $\mathrm{cDCs},{ }^{78,79}$ as the receptor for CSF-1, CD115 is still expressed at the CDP stage and on some pre-DCs during DC development.

\section{Transcriptional control of $\mathrm{cDC}$ development}

cDC development is controlled by multiple TFs serving as master regulators of gene expression modules, which determine differentiation of HSCs toward the distinct CDC subsets. TFs that are crucial for the development and differentiation of $\mathrm{CDCs}$ include Pu.1, RelB, Ikaros, Id2, Notch2, Nfil3, Batf3, Irf4, and Irf8. ${ }^{80-82}$ Although much progress has been made during recent years, the study of the exact role of these TFs in cDC ontogeny has turned out to be challenging, as expression of these TFs is often not restricted to the $\mathrm{cDC}$ lineage. Therefore, mice lacking one of these TFs harbor many defects in lineages other than cDCs, rendering it difficult to distinguish cell intrinsic from cell-extrinsic effects. For example, besides a defect in the cDC1 lineage, mice lacking Irf8 suffer from neutrophilia and have additional defects in the monocyte and B-cell lineages. ${ }^{83-85}$ Moreover, these lineage-determining TFs can function at a very specific step of the CDC developmental pathway or they can be required at multiple steps during $\mathrm{cDC}$ development. In both cases, mice completely lacking a TF will result in a similar outcome making it difficult to identify its precise time point of action. Furthermore, the same TF can be strictly required for the development of one DC subset, while regulating the activation and not the development, of another DC subset (see below). Therefore, constitutive and tamoxifen-inducible Crelox mouse lines are very valuable tools to investigate the exact timing of TF dependency along DC development. For instance, Irf8 was described to be crucial at the MDP to CDP transition in the $\mathrm{BM}$, leading to $\mathrm{CDC} 1$ defect in the periphery. ${ }^{33,86}$ More recently, it was shown that Cd11c-cre-mediated deletion of Irf8, by which Irf8 would not be targeted at the MDP stage given the absence of CD11c expression on this population, also lack cDC1s. ${ }^{33,37,87}$ This implies a role for Irf8 at additional steps during $\mathrm{CDC} 1$ development, further supported by the finding that autoactivation of this $\mathrm{TF}$ is required for the specification of
pre-cDCs toward the cDC1 lineage. ${ }^{32}$ Some TFs are even required to maintain the cellular identity of terminally differentiated cells. Such TFs, of which a typical feature is their autoregulation resulting in continuous high expression throughout the life of the cells they control, were designated "terminal selectors". We recently demonstrated that high levels of Irf8 remain required for the survival of terminally differentiated $\mathrm{cDC} 1 \mathrm{~s}$, identifying Irf8 as a terminal selector of the $\mathrm{cDC} 1$ lineage. $^{33}$ Irf8 is also expressed during the monocyte and $\mathrm{pDC}$ development pathways but plays strikingly divergent roles in these cells. In monocytes, Irf8 is only required at the $\mathrm{cMoP}$ to monocyte transition but is dispensable for development once passed the $\mathrm{cMoP}$ stage. In pDCs, Irf8 is dispensable for both the early and the late stages of development but regulates the activation state of pDCs, as Irf8deficient pDCs display increased T-cell stimulatory function and decreased type 1 interferon production. ${ }^{33}$

The precise step during development where a TF acts, will have a major influence on the outcome of a certain mutation or deletion. Loss of TFs that are involved in early DC development or TFs that are continuously required during DC development will result in the lack of many DC subsets, whereas other TFs are only required for the late differentiation of a specific $\mathrm{cDC}$ subset. For example, lack of Pu.1 results in the absence of all DC subsets, caused by its continuous requirement during DC development. ${ }^{88}$ This is possibly due to the fact that Pu.1 controls Flt3 expression on BM precursors, as Flt3 is critically required for the commitment of $\mathrm{BM}$ precursors toward the DC lineage (see above). Gfil is also required for the development of both $\mathrm{CDC} 1$ and $\mathrm{CDC} 2$ subsets across tissues. ${ }^{89}$ In contrast, Batf3, Nfil3, Id2, and Irf8 are only involved in specification of these progenitors toward the $\mathrm{CDC1}$ and not the $\mathrm{CDC} 2$ lineage. ${ }^{31-34,37,76,87,90-93}$ Another layer of complexity is apparent within the $\mathrm{CDC} 2$ population. To date a number of TFs have been implicated not in the "early" development of these cells but rather late in the differentiation of the cells. For example, Notch2 appears to play a role in a subset of splenic cDC2s expressing ESAM and a subset of intestinal cDC2s expressing $\mathrm{CD} 103^{44,94}$ but no defect in the development of DC precursors has been reported to date. Klf4 has been described to both influence the development of Irf4-expressing pre-cDCs in the $\mathrm{BM}$ as well as the later development of specific $\mathrm{CDC} 2$ subsets such as the $\mathrm{CD} 24^{+} \mathrm{Mgl} 2^{+}$lung $\mathrm{cDC} 2 \mathrm{~s}$ and the $\mathrm{CD} 11 \mathrm{~b}^{-}$ (double negative, DN) dermal cDC2s. ${ }^{95}$ Notch2 deficiency in DCs results in impairment to mount $\mathrm{T}_{\mathrm{H}} 17$ responses $^{44}$ and to produce IL-23, leading to susceptibility against Citrobacter rodentium. ${ }^{94}$ Mice lacking Klf4 in DCs lack $\mathrm{T}_{\mathrm{H}} 2$ but not $\mathrm{T}_{\mathrm{H}} 17$ responses and are susceptible to Schistosoma mansoni infection. ${ }^{92}$ At first sight this may suggest the presence of two different subsets of cDC2s: Klf4-dependent $\mathrm{T}_{\mathrm{H}} 2$-inducing cDC2s and Notch2-dependent $\mathrm{T}_{\mathrm{H}} 17$-inducing cDC2s. Some findings support this model such as the fact that $\mathrm{ESAM}^{+}$ cDC2s are Notch2-depedent but Klf4-independent. Although Notch2- and Klf4-dependent cDC2 subsets are found in many tissues, no conserved surface markers that faithfully permit the distinction between these two putative subsets across tissues 
have been described. Additionally, $\mathrm{CD} 103{ }^{+} \mathrm{CD} 11 \mathrm{~b}^{+}$intestinal cDC2s are Notch2-dependent but also partially Klf4-dependent. Thus, it could also be that while Notch2 and Klf4 are required for the development of some specific $\mathrm{cDC}$ subsets, they may also be required for the production of $\mathrm{T}_{\mathrm{H}} 2$-inducing and $\mathrm{T}_{\mathrm{H}} 17$-inducing cytokines across all cDC2 subsets, including the subsets that still develop in absence of these TFs. Irf4 has also been shown to be crucial only for $\mathrm{CD} 24^{+} \mathrm{cDC} 2 \mathrm{~s}$, but not $\mathrm{CD} 24^{-} \mathrm{cDC} 2 \mathrm{~s}$ in the lung ${ }^{37}$ and the heart (unpublished data), for $\mathrm{CD} 103^{+}{ }^{+} \mathrm{cDC} 2 \mathrm{~s}$ (which also express CD24), but less so for $\mathrm{CD}_{103}{ }^{-} \mathrm{cDC} 2 \mathrm{~s}$ in the intestine ${ }^{35,36}$ and for $\mathrm{CD} 4^{+} \mathrm{cDC} 2 \mathrm{~s}$, but not $\mathrm{CD} 4{ }^{-} \mathrm{cDC} 2 \mathrm{~s}$ in the spleen. ${ }^{37} \mathrm{Irf} 4$ also appears to be crucial for the migration of all $\mathrm{cDC} 2 \mathrm{~s}$ from the periphery to the draining LNs. ${ }^{35,36,38}$ Although it could be that Irf4 differentially regulates the development, survival, and migration of distinct cDC2 subsets, it may also be that Irf4 is generally required for the survival of cDC2s across tissues. We have recently revisited the presence of cDC2s across tissues in Irf4-deficient animals and found a drop of cDC2s in all tissues, ${ }^{30}$ including the skin once we had carefully out-gated contaminating CD64 ${ }^{+} \mathrm{M} \phi \mathrm{s}$, which was not done in all previous studies. ${ }^{38} \mathrm{We}$ in fact hypothesize that the cells remaining in the tissues of Irf4deficient mice are recently developed $\mathrm{cDC} 2 \mathrm{~s}$ that are about to die. As such, we propose that the $\mathrm{CD} 24^{-} \mathrm{CD} 103^{-} \mathrm{CD} 4{ }^{-}$ $\mathrm{cDC} 2 \mathrm{~s}$ that remain in the lung, the intestine, the spleen, and the skin of Irf4-deficient animals represent recently developed cDC2s that will die before or just after acquiring CD24, CD103, $\mathrm{CD} 4$, or CCR7 expression. Premature death of all $\mathrm{CDC} 2$ subsets would also explain the loss of both $\mathrm{T}_{\mathrm{H}} 2^{96-99}$ and $\mathrm{T}_{\mathrm{H}} 17$ responses $^{35,36}$ in mice lacking Irf4 in DCs, assuming they die prior to migration and antigen presentation to naive $\mathrm{T}$ cells. More recently, we have identified Zeb2 as a TF that functions in an intrinsic manner to control cDC2 development across tissues. ${ }^{100}$ Again, this appears to be only in a subset of cDC2s, as a proportion of these cells remain in $\mathrm{CD} 11 c^{\mathrm{CRE}} \mathrm{xZeb} 2^{\mathrm{fl} / \mathrm{fl}}$ animals. ${ }^{100}$ Once more, we could not identify a specific surface marker for the subset of $\mathrm{cDC} 2 \mathrm{~s}$ requiring Zeb2. ${ }^{100}$ This partial reduction in cDC2s in $\mathrm{CD} 11 \mathrm{c}^{\mathrm{CRE}} \mathrm{xZeb2}{ }^{\mathrm{fl} / \mathrm{fl}}$ mice has since been reported independently by the group of Ken Murphy. ${ }^{101}$ Moreover, they found similar partial reductions in $\mathrm{CDC} 2 \mathrm{~s}$ both in vivo and in vitro when using inducible CRE systems including the $\mathrm{Mx}{ }^{\mathrm{CRE}}$ mice. ${ }^{101}$ Notably, they propose that Zeb2 does not control (even in part) the cDC2 lineage, rather suggesting that Zeb2 exerts its effects through repressing the cDC1 lineage. ${ }^{101}$ However, in our view, this would not explain the cell intrinsic reduction seen by both the groups in the cDC2 population, ${ }^{100,101}$ thus further investigation into the role of Zeb2 in cDC development and differentiation is warranted. In general, it is clear from the many bifurcations within the cDC2 subset in terms of their dependence on distinct TFs demonstrate that we do not yet fully understand this intriguing $\mathrm{cDC}$ subset. Single-cell technologies such as single-cell RNA-seq should help to address these issues and will hopefully help us to understand whether multiple cDC2 subsets truly exist or whether we are mainly dealing with activation states and/or developmental intermediates.

\section{cDC SUBSETS IN BARRIER TISSUES}

With the advent of multiparameter flow cytometry, our understanding of the $\mathrm{CDC}$ populations present in the different barrier tissues has greatly increased in recent years. However, despite this, the analysis of the $\mathrm{cDC}$ subsets present in each tissue has evolved separately resulting in a number of different markers being used to differentiate between cDC subsets in each tissue. As a result it has become difficult to compare the subsets present in each tissue. As the recently proposed $\mathrm{cDC} 1$ and cDC2 nomenclature will allow us to uniformly classify the cDC subsets across tissues, it will be used below where possible (Figure 2 and Table 1).

\section{Intestine}

Considerable research effort has focused on the identification of the various $\mathrm{CDC}$ subsets in the intestines and their distinction from other mononuclear phagocytes. In the intestine, cDCs can be found in the lamina propria (LP), the thin layer of loose connective tissue that together with the overlying epithelium constitute the mucosa. ${ }^{102}$ In mice, cDCs can be identified as $\mathrm{CD}_{4}{ }^{+}$Lineage ${ }^{-} \mathrm{CD} 11 \mathrm{c}^{\text {hi }} \mathrm{MHCII}{ }^{+} \mathrm{CD} 4^{-} \mathrm{F} 4 / 80^{\text {lo }}$ cells in both the small and large intestine. Identifying them on this basis allows them to be distinguished from intestinal CD64 ${ }^{+}$ F4/80 ${ }^{\text {hi }} \mathrm{M} \phi$ s that also express CD11c and MHCII. ${ }^{10,12,28}$ Studies have shown that these cells, as expected for cDCs, are Flt3L-dependent, express $\mathrm{zDC}$, and derive from pre-cDCs not monocytes. ${ }^{12,103}$ Intestinal $\mathrm{M} \phi$, which develop from embryonic progenitors in the embryo but later require continual replenishment from BM monocytes, are Flt3L-independent and lack zDC expression instead expressing the monocyte-/m $\phi$-associated TF, $M a f b .^{6}$ In the intestines, cDCs are commonly further divided into subsets on the basis of CD103 and CD11b expression. This leads to the identification of four distinct subsets of $\mathrm{cDCs}: \mathrm{CD}_{103}{ }^{+} \mathrm{CD} 11 \mathrm{~b}^{-}, \mathrm{CD} 103^{+} \mathrm{CD} 11 \mathrm{~b}{ }^{+}$, $\mathrm{CD}_{103}{ }^{-} \mathrm{CD}_{11 b^{+}}$, and $\mathrm{CD} 103^{-} \mathrm{CD}_{11 b^{-}} \mathrm{cDCs}$. Importantly all four subsets can also be found migrating in lymph and in the gut-draining mesenteric LNs among the $\mathrm{CD}_{11 \mathrm{c}}{ }^{+} \mathrm{MHCII}^{\mathrm{hi}}$ cells. ${ }^{12,36,104-106}$ Notably, the relative proportions of the distinct cDC subsets varies between the small intestine (SI) and colon, with the $\mathrm{CD} 103^{+} \mathrm{CD} 11 \mathrm{~b}{ }^{+} \mathrm{cDCs}$ predominating in the SI and the $\mathrm{CD}_{103}{ }^{+} \mathrm{CD}_{11 \mathrm{~b}}{ }^{-} \mathrm{cDCs}$ being the major subset in the colon. ${ }^{12,107,108}$ The exact reason for this difference is unclear, but it is hypothesized to be a result of the presence of distinct microbiota at each site. ${ }^{108}$ Indeed, we have also noted differences in the relative proportions of the distinct $\mathrm{cDC}$ subsets in the SI LP of mice from different animal houses (unpublished data).

The presence of the $\mathrm{CD} 03^{+} \mathrm{CD} 11 \mathrm{~b}^{+} \mathrm{cDCs}$ in the LP is somewhat unique, as these cDCs have only recently been described in one other tissue outwith the intestine during homeostasis, the nasal mucosa ${ }^{109}$ (see below). On the other hand, the presence of the $\mathrm{CD} 103^{-} \mathrm{CD}^{-11 b^{-}} \mathrm{CDC}$ population in the LP itself is debatable as these cDCs are significantly reduced in the SI LP of ROR $\gamma \mathrm{t}^{-/-}$mice, which lack all secondary lymphoid tissues except the spleen. ${ }^{104}$ This suggests that these cells primarily derive from isolated lymphoid follicles rather 
a

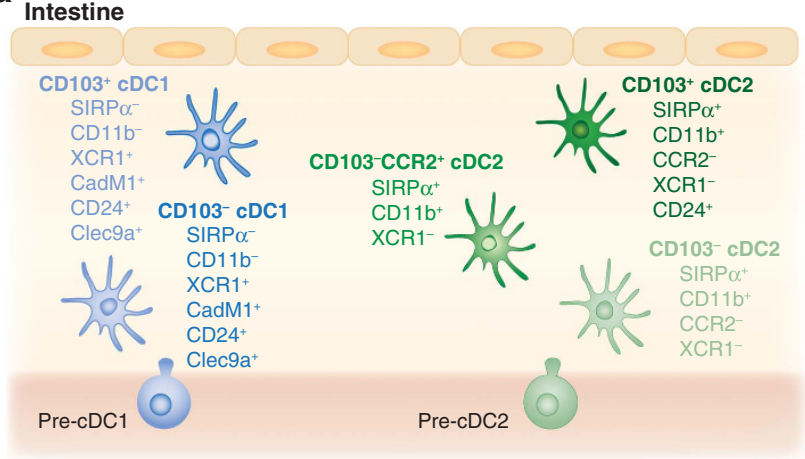

b

Lung

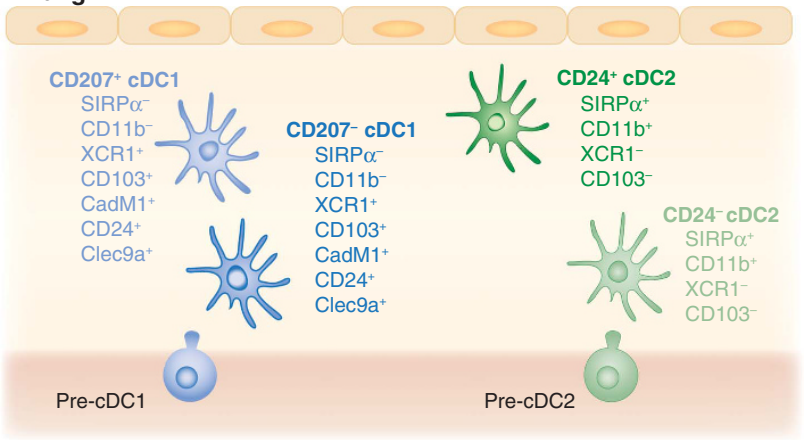

c

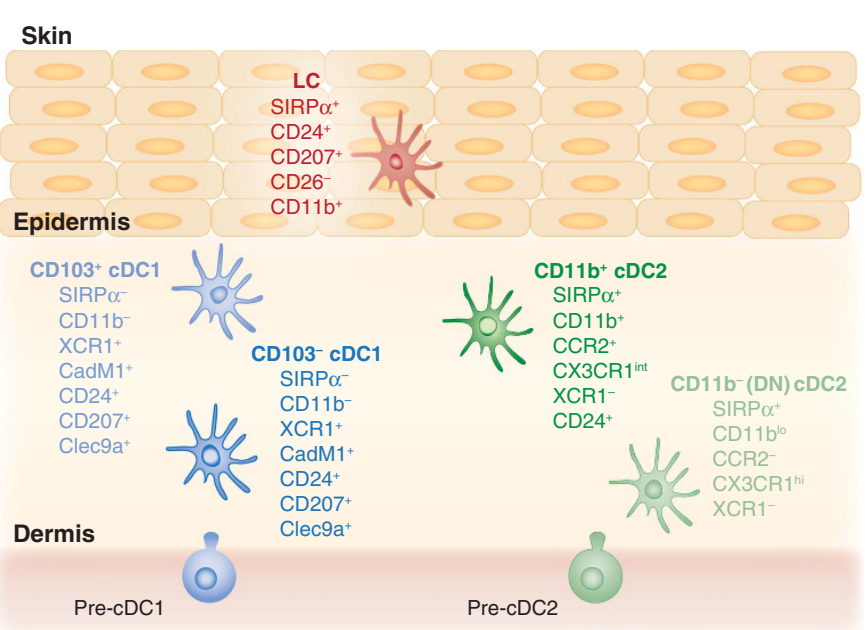

$d_{\text {Nose }}$

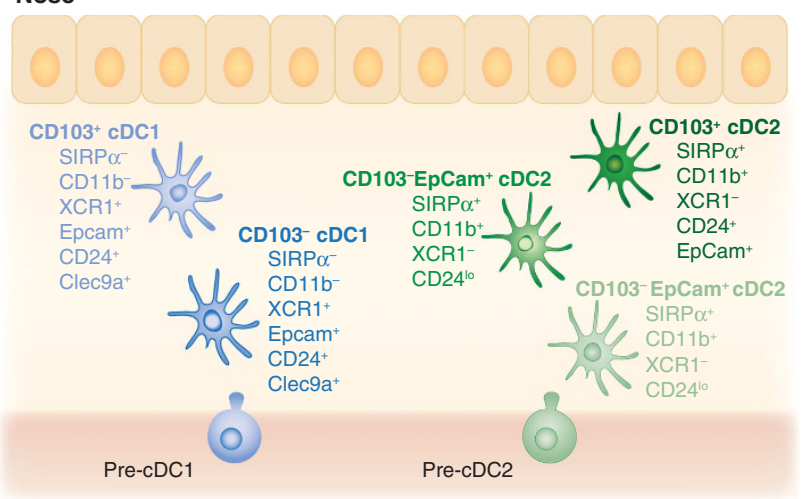

e

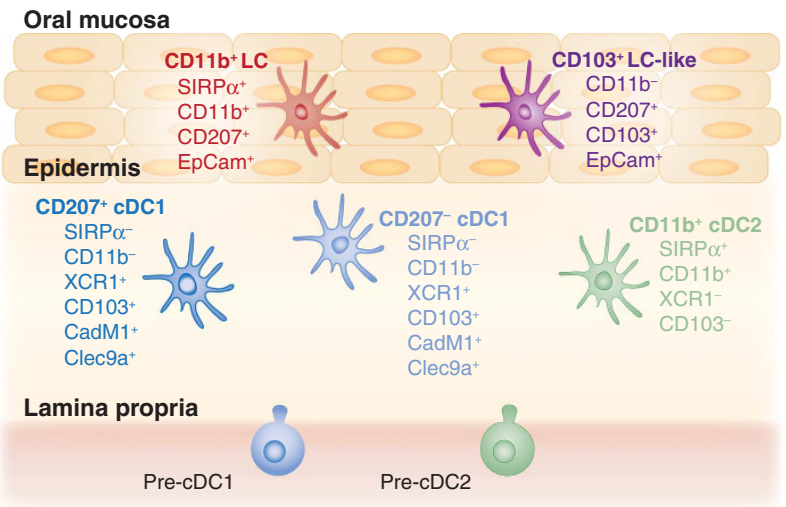

Figure 2 CDC-and DC-like subsets in barrier tissues. The distinct populations of CDC1s (different shades of blue), cDC2s (different shades of green), LCs (red), and LC-like cells (purple) are shown in the (a) intestine, (b) lung, (c) skin, (d) nasal mucosa and (e) oral mucosa. cDC, conventional dendritic cell; DC, dendritic cell; LCs, Langerhans cells.

than the LP itself. Note that Peyer's patches are removed prior to the digestion of the SI and these cDCs are also found in the colon, which is devoid of Peyer's patches.

Applying the $\mathrm{CDC} 1$ and $\mathrm{CDC} 2$ nomenclature also gives you four subsets: $\mathrm{CD}_{103}{ }^{+} \mathrm{cDC} 1 \mathrm{~s}, \mathrm{CD} 103^{-} \mathrm{cDC} 1 \mathrm{~s}, \mathrm{CD} 103^{+}$ $\mathrm{cDC} 2 \mathrm{~s}$, and $\mathrm{CD}_{103}{ }^{-} \mathrm{cDC} 2 \mathrm{~s}$. Importantly, using $\mathrm{CD} 172 \mathrm{a}$ $(\operatorname{SIRP} \alpha)$ rather than $\mathrm{CD} 11 \mathrm{~b}$, while not affecting the $\mathrm{CD} 103^{+}$ subsets does edit the composition of the $\mathrm{CD}_{103}{ }^{-}$subsets, as some of the $\mathrm{CD}_{103}{ }^{-} \mathrm{CD}_{11} \mathrm{~b}^{-}$cDCs do express CD172a ${ }^{104,110}$ and represent a minor fraction of $\mathrm{cDC} 2 \mathrm{~s}$. In addition to these markers, intestinal $\mathrm{CD} 103^{+} \mathrm{cDC} 1 \mathrm{~s}$ also express CD24, Cadm1, Clec9A (DNGR-1) and in the SI CD8 $\alpha \cdot{ }^{103,104}$ It is unclear if CD8 $\alpha$ is absent from the $\mathrm{cDC} 1 \mathrm{~s}$ in the colon or if the enzyme cocktail used to dissociate the colon cleaves it. Intestinal $\mathrm{CD}_{103}{ }^{+} \mathrm{cDC} 2 \mathrm{~s}$ also express CD24. ${ }^{35}$ It has recently been shown that the $\mathrm{CD} 103^{-} \mathrm{CDC} 2 \mathrm{~s}$ can be further segregated on the basis of CCR2 expression. ${ }^{12}$ This was somewhat unexpected given the association of CCR2 with monocyte-derived cells and the fact that $\mathrm{CD}_{103}{ }^{-} \mathrm{cDC} 2 \mathrm{~s}$ derive from pre-cDCs, but suggests that care should be exercised when defining $\mathrm{cDCs}$ as 
Table 1 Summary of $\mathrm{CDC}$ subsets in barrier tissues

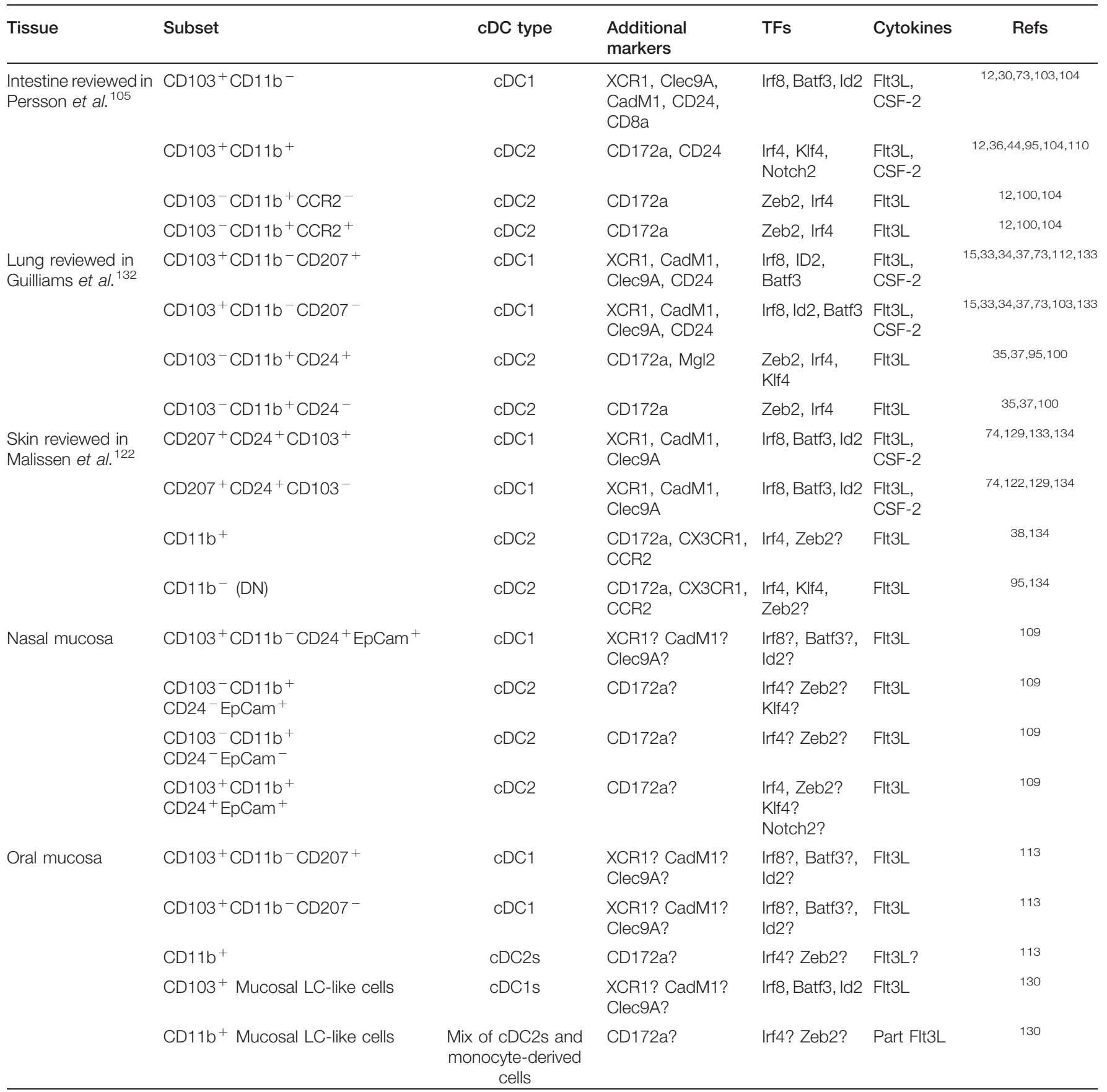

cDC, conventional dendritic cell; LC, Langerhans cells; TFs, transcription factor.

CCR2-independent. Indeed other work from our lab has identified a proportion of CCR2 ${ }^{+} \mathrm{cDC} 2 \mathrm{~s}$ also in the spleen and lung ( $\sim 20 \%$ in lung cDC2s, $\sim 5 \%$ in spleen $\mathrm{cDC} 2 \mathrm{~s}$, unpublished data) suggesting that this observation is not specific to the intestine.

Crucially, all the cDC subsets described in the murine intestine can also be identified in the human SI and colonic LP..$^{12,36,111}$ In human tissue CD103 and CD172a are often used to define the subsets. In addition, we have recently shown that Cadm1 expression is conserved in humans and so could be used to identify the cDC1s prior to analysis of CD103 expression (unpublished data). Human intestinal $\mathrm{cDC} 1 \mathrm{~s}$ also express CD141 (BDCA3) and Clec9a, ${ }^{36,111}$ whereas human cDC2s also express CD1c (BDCA1). ${ }^{11}$ Human intestinal $\mathrm{CD}_{103}{ }^{-}$cDC2s were also found to express CCR2, ${ }^{12}$ as in the mouse.

\section{Lung}

In the lung, similarly to the intestine, it is common to differentiate between DC subsets using CD103 and CD11b 
expression. This results in the identification of two populations: the $\mathrm{CD} 103^{+} \mathrm{CD}_{11 \mathrm{~b}}{ }^{-} \mathrm{cDC} 1 \mathrm{~s}$ which also express XCR1, CadM1, and CD24, ${ }^{15,30,37,100}$ and $\mathrm{CD} 103^{-} \mathrm{CD} 11 b^{+} \mathrm{DCs}$, which also express CD172a. Interestingly, a considerable proportion of the cDC1s also express CD207 (langerin), ${ }^{34,112}$ a marker primarily associated with Langerhans cells (LCs) in the skin. These cDC1s expressing CD103 and CD207 are located in close contact with the lung epithelial cells. ${ }^{112}$ Importantly, this is not the only example of cDCs expressing CD207 as cDC1s in the dermis, liver, kidney, and CDC1s and cDC2s in the oral mucosa (see below) can also express CD207. ${ }^{34,113}$ Notably, however, the proportion of cDCs expressing CD207 is different from one mouse strain to another. $^{114}$

Unlike in the intestine, where $\mathrm{CD} 64^{+} \mathrm{F} 4 / 80^{\mathrm{hi}} \mathrm{M} \phi$ s are first out-gated prior to the identification of $\mathrm{cDCs}$, common practice in the lung, whereby $\mathrm{CD} 11 \mathrm{c}^{+} \mathrm{MHCII}^{+}$cells are identified prior to outgating $\mathrm{CD} 64^{+}$cells, means that the $\mathrm{CD} 11 \mathrm{~b}^{+}$ "DCs" in the lung are routinely contaminated with CD64 ${ }^{+}$ $\mathrm{CD}_{11 \mathrm{c}^{+}} \mathrm{MHCII}^{+}$monocyte-derived cells. Although these are often referred to as moDCs, it is unclear if these represent a bona fide DC population, as they have been found to function poorly as antigen-presenting cells and do not appear to routinely migrate to the draining lymph node. ${ }^{15}$ Furthermore, these cells also lack expression of zDC and express Mafb ${ }^{6}$ suggesting that, as in the gut, these are a population of bona fide $\mathrm{m} \phi \mathrm{s}$ (from herein referred to as moM $\phi \mathrm{s}$ ). These $\mathrm{moM} \phi \mathrm{s}$ can be distinguished from the genuine $\mathrm{CD} 11 \mathrm{~b}^{+} \mathrm{cDC} 2 \mathrm{~s}$ in the lung on the basis of CD64, MerTK, and CD26 expression as CDC2s are $\mathrm{CD}_{26}{ }^{+} \mathrm{CD} 4^{-}{ }^{-} \mathrm{MerTK}^{-}$, whereas moM $\phi$ s express CD64 and MerTK but lack expression of CD26. ${ }^{15,25,26}$ Lung cDC2s also express CD172a and a subset of them also express CD24. ${ }^{37} \mathrm{We}$ have previously described Mar-1 to be a marker of the moM $\phi$ population in the lung following HDM administration, identifying the cells as $\mathrm{CD} 64^{+}$Mar- $1^{+} .{ }^{15}$ Following a high dose of house dust mite, we could find $\mathrm{Mar}^{-1}{ }^{+}$cells in the draining mediastinal LN, but the expression of CD64 by these cells was significantly lower than by those in the lung. Although these cells were not identified in the recent Mafb study from $\mathrm{Wu}$ and colleagues, their experimental setup differed from ours. Thus it will be interesting to more closely characterize these cells in the future to determine their true nature.

Similar subsets of cDCs can be identified in the human lung, where it is common to use CD141 and CD1c expression to delineate $\mathrm{cDC} 1 \mathrm{~s}$ and $\mathrm{cDC} 2 \mathrm{~s}$, respectively. ${ }^{115,116}$ Interestingly, however, CD207 is not found on human CDC1s, but instead low levels of this lectin were shown to be expressed on the CD1c ${ }^{+}$ cDC2 population. ${ }^{115}$ Similar observations were also made in pigs, ${ }^{117}$ highlighting a difference between species regarding CD207 expression. In humans, CD207 expression could be induced on blood $C D C 2$ s by TSLP and TGF- $\beta .^{115,118}$ Although studies in mice indicated that murine CD207 could also be regulated by TGF- $\beta,{ }^{119,120}$ it remains unclear if TGF- $\beta$ regulates $\mathrm{CD} 207^{+} \mathrm{cDC} 1 \mathrm{~s}$. Note that murine $\mathrm{CD} 207^{+} \mathrm{cDC} 1 \mathrm{~s}$, porcine $\mathrm{CD}_{20}{ }^{+} \mathrm{cDC} 2 \mathrm{~s}$, and human $\mathrm{CD} 207^{+} \mathrm{cDC} 2 \mathrm{~s}$ have all been located in close contact to the lung epithelial cells. ${ }^{112,117,121}$ This suggests that $\mathrm{CD} 207$ expression is imprinted by the local lung epithelial microenvironment, possibly via TGF- $\beta$, regardless of the distinct ontogeny of the $\mathrm{CD} 207^{+} \mathrm{cDC}$ subsets in these species.

\section{Skin}

In the skin, cDCs are found predominantly in the dermis and similarly to other tissues these can be subdivided into $\operatorname{Irf8} 8^{\text {hi }}$ cDC1s and Irf $4{ }^{\mathrm{hi}} \mathrm{cDC} 2 \mathrm{~s}$. All cDC1s in the dermis express CD24 and CD207, however distinct from most other non-lymphoid tissues, dermal $\mathrm{cDC} 1 \mathrm{~s}$ can be further subdivided into two discrete populations on the basis of CD103 expression. ${ }^{122,123}$ Dermal CD172 $\mathrm{a}^{\text {hi }} \mathrm{cDC} 2 \mathrm{~s}$ express high to intermediate levels of CCR2 and CX3CR1, and can be further subdivided based on $\mathrm{CD} 11 \mathrm{~b}$ expression. CD11b $\mathrm{b}^{\mathrm{lo}} \mathrm{cDC} 2 \mathrm{~s}$, often referred to as "double negative" cDCs, express only low levels of CD11c. The separation of skin CDC2s based on CD11b expression is partially correlated with differences in their TF dependency and function. Both cDC2 subsets express high levels of Irf4 and display decreased migration in Irf4-deficient mice, ${ }^{37,38,95}$ however as in the intestine, ${ }^{36}$ this reduction in $\mathrm{cDC} 2 \mathrm{~s}$ in the LN could be the result of increased cell death rather than lack of migration. Others demonstrated that Irf4-dependent migratory $\mathrm{cDC} 2 \mathrm{~s}$ are required for $\mathrm{T}_{\mathrm{H}} 2$ cell polarization following cutaneous challenge and these $\mathrm{cDC} 2 \mathrm{~s}$ were specifically characterized by the expression of PD-L2 and Mgl2 (CD301b). ${ }^{98,124}$ Besides Irf4, Klf4 has also been implicated in the development of dermal cDC2s. In mice deficient for Klf4, CD11 b ${ }^{\text {hi }}$ cDC2s were reduced by $50 \%$ in the dermis and in the skin-draining LNs DN cDC2s were completely abrogated. Cutaneous $\mathrm{T}_{\mathrm{H}} 2$ responses are abolished in absence of Klf4 $4^{95}$ and it was therefore postulated that the Klf4dependent $\mathrm{DN}$ cDC2s are the main inducers of $\mathrm{T}_{\mathrm{H}} 2$ responses in the skin. ${ }^{95}$ However, we have found that both dermal $\mathrm{CD}_{11} \mathrm{~b}^{+} \mathrm{cDC} 2 \mathrm{~s}$ and dermal CD11b ${ }^{-} \mathrm{DN}$ cDC2s can induce potent $\mathrm{T}_{\mathrm{H}} 2$ responses (Deckers et al., in press). Or, there is a yet unidentified subset of Klf4-dependent CD11b ${ }^{+}$cDC2s that excel in $\mathrm{T}_{\mathrm{H}} 2$ induction. Or, Klf4 is required for the $\mathrm{T}_{\mathrm{H}} 2$ inducing capacities of the $\mathrm{CD} 11 \mathrm{~b}^{+} \mathrm{cDC} 2 \mathrm{~s}$ that are remaining in Klf4-deficient mice.

During inflammation, monocyte-derived cells are recruited to the skin. As in the gut and the lung, these cells express CD11c, MHCII, CD11b, and thus must be distinguished from cDC2s. This is achieved by examining expression of CD64 and MerTK both of which are expressed at intermediate levels by the monocyte-derived cells but are absent from cDC2s. In addition to cDCs and monocyte-derived cells, the skin also contains another subset of cells termed LCs, which reside primarily in the epidermis but can migrate through the dermis to the draining lymph node. The classification of LCs is a matter of debate. Given their DC-like morphology, their expression of MHCII, CD11c, CD24, CD207, and CD172a and their ability to migrate to the LN in a CCR7-dependent way, they were historically classified as DCs. However, more recently it has become clear that LCs do not represent a CDC population, as they do not derive from DC-committed progenitors and 
instead derive from embryonic progenitors which seed the developing skin before birth and then self-renew throughout life, reminiscent of most tissue-resident $\mathrm{M} \phi$ populations. ${ }^{125,126}$ Accordingly, they are not dependent on Flt3-Flt3L signaling, but on IL-34/CSF1R signaling. Although LCs were classically distinguished from cDCs based on their radioresistance compared with cDCs which are radiosensitive, ${ }^{127-129}$ it has recently been shown that LCs can be distinguished from skin cDCs on the basis of CD26 and CD24 expression, with LCs being $\mathrm{CD} 26^{\mathrm{lo}} \mathrm{CD} 24^{\mathrm{hi}}$, whereas cDCs are $\mathrm{CD} 26^{\text {hi25,30 }}$. Moreover, expression of Zbtb46 and Mafb can be used to identify LCs as consistent with LCs possessing both DC and M $\phi$ qualities, LCs are, to date, the only cell found in vivo, which express both Zbtb46 and Mafb. ${ }^{6}$ Thus by using these markers, the need for irradiation can be avoided, which may have significant effects on the functionality of these cells and on skin biology in general.

A fraction of dermal CD11b ${ }^{+} \mathrm{cDC} 2 \mathrm{~s}$ express Aldh1a2 and possess the capacity to produce retinoic acid, ${ }^{123}$ an essential compound for the generation of induced $\mathrm{T}_{\mathrm{Reg}}$ in the periphery. In the intestine, it is however the $\mathrm{CD} 103^{+} \mathrm{cDC} 1 \mathrm{~s}$ that possess the highest retinoic acid-producing capacity. Together with the variable CD207 expression in lung DCs according to species described above, this again underlines that some functions are modular and can be acquired by distinct subsets in different tissues, suggesting the presence of distinct microenvironments that are populated by distinct DC subsets but that can imprint similar functions.

\section{Nasal mucosa}

Although $\mathrm{cDCs}$ in the nasal mucosa have not yet been extensively studied, an elegant investigation into the $\mathrm{cDC}$ subsets in the nose was recently published. ${ }^{109}$ This study revealed that cDCs in the nose can be divided into those present in the nasal-associated lymphoid tissues (NALT) and those present in the nasal passages (non-NALT). As in other tissues, nasal mucosa cDCs can be distinguished from $\mathrm{m} \phi \mathrm{s}$ based on CD64 and F4/80 expression as well as by their expression of the DC-specific TF Zbtb46 and their dependence on Flt3L. Both NALT and non-NALT tissue contains $\mathrm{CDC1}$ s (characterized as $\mathrm{CD} 103^{+} \mathrm{CD}_{11 \mathrm{~b}}{ }^{-} \mathrm{CD} 24^{+} \mathrm{EpCam}{ }^{\mathrm{hi}}$ ) that in contrast to most lymphoid tissue $\mathrm{cDC} 1 \mathrm{~s}$ and $\mathrm{cDC} 1 \mathrm{~s}$ in the intestine do not express $\mathrm{CD} 8 \alpha$. As described in the lung, there is also a small subset of cDC1s in the nasal mucosa that express CD207. However it is unclear how these correlate to the $\mathrm{CD} 103^{+}$ $\mathrm{CD}_{11 \mathrm{~b}}{ }^{-} \mathrm{cDC} 1 \mathrm{~s}$ as co-staining was not reported. ${ }^{109} \mathrm{cDC} 2 \mathrm{~s}$ (characterized as $\mathrm{CD} 103^{-} \mathrm{CD} 11 \mathrm{~b}^{+} \mathrm{CD} 24^{\text {lo }}$ cells) that could be further segregated on EpCam expression ${ }^{109}$ were also identified in both the NALT and non-NALT tissue. Interestingly, the nonNALT tissue also harbors a population of $\mathrm{CD} 103^{+} \mathrm{CD} 11 \mathrm{~b}^{+}$ $\mathrm{CD} 24^{+}$EpCam $^{+}$cDC2s. ${ }^{109}$ This is the first description of such a $\mathrm{CDC}$ population in the steady state outwith the gut. As the factors inducing the differentiation of this specific $\mathrm{CDC}$ population remain largely unknown (see below), it is interesting to speculate that similar factors may be involved in the two locations. Thus, it will be interesting to compare the $\mathrm{CD} 103^{+} \mathrm{CD} 11 \mathrm{~b}^{+} \mathrm{cDCs}$ in the intestine with those in the nasal mucosa to evaluate whether these cells have a shared developmental pathway and/or a similar functional specialization.

\section{Oral mucosa}

The tissue lining the oral cavity is commonly referred to as the oral mucosa. Similar to other mucosal tissues, a number of DC subsets exist in the oral mucosa. The precise subsets of DCs identified also depends on where in the oral mucosa one looks. Typically, the oral mucosa is divided into the buccal, sublingual, and gingival mucosa. DCs in the oral mucosa have historically been divided into interstitial DCs (iDCs) and LCs due to the similarities between the oral mucosa and the skin. iDCs are bona fide $\mathrm{cDCs}$ that can be further subdivided into $\mathrm{CD} 11 \mathrm{~b}^{-}$ and $\mathrm{CD} 11 \mathrm{~b}^{+}$subsets, ${ }^{113}$ likely cDC1s and $\mathrm{CDC} 2 \mathrm{~s}$. In the buccal mucosa, $\mathrm{CD}_{11 b^{-}}$iDCs also express $\mathrm{CD} 103$ as has been observed in the majority of non-lymphoid tissues. A minor population of these $\mathrm{CD} 103^{+}$iDCs has also been reported in the gingival mucosa. Furthermore, a subset of $\mathrm{CD} 103^{+}$iDCs in the buccal mucosa, as in the lung and nasal mucosa also express CD207. ${ }^{113}$

Classification of LC-like cells present in the epithelium of oral mucosa is particularly challenging. $\mathrm{CD}_{11 \mathrm{c}^{+}} \mathrm{MHCII}^{+}$ $\mathrm{CD}_{207}{ }^{+} \mathrm{EpCam}^{+}$cells present in mucosal epithelia resemble epidermal LCs transcriptionally but have a distinct cellular origin. Moreover mucosal LC-like cells can be further divided into a $\mathrm{CD}_{103}{ }^{+}$and a CD11b ${ }^{+}$fraction. ${ }^{130}$ The $\mathrm{CD} 103^{+}$LClike cells derive exclusively from pre-cDCs not embryonic progenitors or monocytes and are dependent on Flt3L, Irf8, and Id2 defining them as genuine $\mathrm{CDC} 1 \mathrm{~s}$ based on their ontogeny. The CD11b ${ }^{+}$LC-like cells derive from both circulating precDCs and circulating monocytes, ${ }^{130}$ and are only partially Flt3L-dependent, suggesting that only part of these cells represent $\mathrm{cDC} 2 \mathrm{~s}$. Further studies will thus be required to disentangle the pool of LC-like cells present in the epithelium of oral mucosa.

\section{DEVELOPMENT AND FUNCTION OF CDC SUBSETS IN BARRIER TISSUES}

The presence of the distinct populations of $\mathrm{cDC} 1 \mathrm{~s}$ and $\mathrm{CDC} 2 \mathrm{~s}$ in different tissues (Figure 2) raises a number of questions. For example, how alike are these subsets? Does CD207 or CD103 expression in different $\mathrm{CDC1}$ subsets reflect a functional specialization of distinct subsets of $\mathrm{CDC} 1 \mathrm{~s}$ and $\mathrm{CDC} 2 \mathrm{~s}$ in each tissue? How do the distinct subsets arise? Are there distinct progenitors giving rise to these different subsets? If it is the same progenitor then what are the local factors in the tissues resulting in the specification of these distinct subsets? Are the populations located differently within each tissue? Do the distinct subsets have altered dependencies on specific TFs? Or does expression of these markers merely represent a final maturation step?

Currently very little is understood regarding these questions. The recent identification of the bifurcation among pre-cDCs leading to a pre-cDC1 and a pre-cDC2 population ${ }^{32,62}$ could 
hint that distinct populations of progenitors could be present. This was previously proposed, following the identification of an $\alpha 4 \beta 7$-expressing progenitor that was suggested to preferentially give rise to gut $\mathrm{CD} 103^{+}$DCs. ${ }^{131}$ However, the gating strategy used to define these progenitors rendered it difficult to compare these cells with the generic pre-cDC population. Our own reanalysis of the single-cell transcriptomic data from the pre-cDC development pathway generated by the lab of Florent Ginhoux, has identified that a small proportion of cells from the CDP stage onwards do express various levels of $\operatorname{Itg} b 7$, the gene encoding the $\beta 7$ subunit of $\alpha 4 \beta 7$ ( $\sim 25 \%$ of CDPs, unpublished data). This may represent the $\alpha 4 \beta 7$-expressing progenitors proposed to preferentially give rise to intestinal DCs but this remains to be demonstrated.

Looking to the cDCs for clues, we and others have recently compared the transcriptomes of $\mathrm{cDC} 1 \mathrm{~s}$ and $\mathrm{cDC} 2 \mathrm{~s}$ across tissues. On one hand, this revealed important differences from one tissue to another with $\mathrm{cDC} 2 \mathrm{~s}$ having typically between 500 to 1,000 genes differing in pairwise comparisons from one tissue to another. Importantly, such differences can also be found between $\mathrm{CDC} 2$ subsets within the same tissue. Dermal $\mathrm{CD}_{11} \mathrm{~b}^{+} \mathrm{cDC}_{2} \mathrm{~s}$ have about 600 differentially expressed genes as compared with dermal $\mathrm{CD}_{11 \mathrm{~b}}{ }^{-}$(DN) $\mathrm{cDC} 2 \mathrm{~s}^{95}$ and intestinal $\mathrm{CD} 103{ }^{+} \mathrm{CD}_{11 \mathrm{~b}}{ }^{+} \mathrm{cDC} 2 \mathrm{~s}$ have $\sim 180$ differentially expressed genes as compared with intestinal $\mathrm{CD}_{103^{-}}$ $\mathrm{CD}_{11 b^{+}} \mathrm{cDC} 2 \mathrm{~s}$. On the other hand, it seems impossible to find a unique tissue-specific $\mathrm{cDC}$ signature, as a comparison between the intestinal $\mathrm{CD} 103^{+} \mathrm{CD} 11 \mathrm{~b}^{+}{ }^{\mathrm{cDC}} 2 \mathrm{~s}$ and the pool of all cDC2s from other tissues, identifies only one gene to be exclusively expressed in intestinal $\mathrm{CD}_{103}{ }^{+} \mathrm{CD} 11 \mathrm{~b}^{+} \mathrm{cDC} 2 \mathrm{~s}$ (Gp2, unpublished data). This gene does not appear to be expressed at any stage of DC development (unpublished data) and this potentially argues against a model where distinct precDC-subsets would give rise to unique tissue-specific cDC subsets. Rather, this may support a model in which cDCs acquire overlapping gene expression profiles according to the particular mix of local signals that cDC precursors sense in the microenvironment during their development (Figure 3).

The identification of the signals that confer the tissue-specific (but overlapping) gene expression profiles to each of the distinct DC subsets will not be a menial task as there are a considerable number of variables to take into account. These factors could derive from the distinct cell types present in each tissue, or from non-self elements such as the local microbiota, food particles, and inhaled particles, or could be the result of the mechanical processes that occur in each tissue such as peristalsis in the gut or breathing in the lungs.

One aspect in which CDC subsets differ across tissues and even within tissues is the distinct requirement for specific TFs. For the CDC2 lineage, as discussed above, a number of examples of differential requirements on specific TFs are known. Taking Zeb2 as an example, we found that although a subset of cDC2s in all tissues were susceptible to the loss of this TF, including the $\mathrm{CD}_{103}{ }^{-} \mathrm{cDC} 2 \mathrm{~s}$ in the intestine, Zeb2 was completely dispensable for the gut $\mathrm{CD}_{103}{ }^{+} \mathrm{cDC}_{2} \mathrm{~s}^{100}$ The gut $\mathrm{CD} 103^{+}$ $\mathrm{cDC} 2 \mathrm{~s}$ also require Notch2 signaling, which, outwith the intestine, has only also been reported for a subset of CDC2s expressing ESAM in the spleen. ${ }^{4,94}$ Importantly, the functional consequences of these differential requirements on individual TFs remain largely unknown. For example, cDC2s are associated with $\mathrm{T}_{\mathrm{H}} 2, \mathrm{~T}_{\mathrm{H}} 17$, and $\mathrm{T}_{\mathrm{Reg}}$ responses, however it is unclear if any $\mathrm{cDC} 2$ can generate any of these responses or if there are additional subsets within the $\mathrm{CDC} 2 \mathrm{~s}$, which would preferentially induce one of these responses and if distinct TFs regulate this. For example, $\mathrm{CD}_{103}{ }^{+} \mathrm{cDC} 2 \mathrm{~s}$ in the intestine have been suggested to drive $\mathrm{T}_{\mathrm{H}} 17$ responses and these $\mathrm{cDCs}$ are dependent upon Irf4 and Notch2 for their generation, but do not require Zeb2. ${ }^{35,36,44,94,100}$ Does this mean Zeb2 is dispensable for $\mathrm{T}_{\mathrm{H}} 17$ responses? As a counter argument, $\mathrm{CCR} 2{ }^{+} \mathrm{CD} 103^{-}{ }^{-} \mathrm{CDC} 2 \mathrm{~s}$ in the gut have also been shown to drive $T_{H} 17$ responses and this subset was reduced in the absence of Zeb2. Does this mean that $\mathrm{T}_{\mathrm{H}} 17$ responses may in fact be affected by the lack of Zeb2 ? $^{100}$ All this is very difficult to predict and will have to be tested experimentally.

Multiple subsets of $\mathrm{cDC} 1 \mathrm{~s}$ and $\mathrm{cDC} 2 \mathrm{~s}$ have been described within various tissues. First of all, we hypothesize that many so-called subsets represent developmental intermediates. A lot of CD207 ${ }^{-}$cDC1s may in fact represent recently developed cDC1s that will acquire CD207 tomorrow once they reach the lung epithelial barrier. However, some $\mathrm{CDC} 1$ s may never reach the epithelial barrier and may develop in other locations within the lung tissue. We therefore hypothesize that some cDC subsets will indeed represent cells that are located in different microenvironments and this we believe will be the major factor determining their differential surface marker expression, TF dependency, transcriptomic profile, and functional specialization. We therefore favor a model in which pre-cDCs segregate in only two main subsets of pre-cDC1s and pre-cDC2s in the $\mathrm{BM}$. These precursors then seed various tissues and colonize distinct microenvironments within tissues. A given $\mathrm{CDC}$ subset expressing marker-X will be located in the microenvironment$\mathrm{X}$, where it acquires a given gene expression profile $\mathrm{X}$ and associated functional specialization due to signals- $\mathrm{X}$ and via TFs-X. This therefore more closely resembles a particular activation state related to its location rather than a complete separate subset as compared with another $\mathrm{CDC}$ expressing marker-Y (Figure 3). This also implies that all these subsets generated in steady state will encounter a very different microenvironment during inflammation, which would imply important plasticity of these cells. We are therefore not favoring a model where marker-X expressing $\mathrm{CDC} 2 \mathrm{~s}$ are linked to a $\mathrm{T}_{\mathrm{H}} 2$ inducing capacity, whereas marker-Y expressing $\mathrm{CDC} 2 \mathrm{~s}$ are linked to a $\mathrm{T}_{\mathrm{H}} 17$-inducing capacity, for example. In fact, if we consider most of these subsets as activation states, during inflammation we may conceive the generation of a $\mathrm{T}_{\mathrm{H}} 2$ inducing microenvironment imprinting $\mathrm{T}_{\mathrm{H}} 2$ capacity on any cDC2s recruited to that location. This would give rise to pro$\mathrm{T}_{\mathrm{H}} 2 \mathrm{cDC} 2 \mathrm{~s}$ that cannot be specifically linked to one or the other marker-X or marker-Y expressing CDC2 subsets that were present in steady state. At this stage these are pure speculations and we are now designing experiments to start to test this theoretical model experimentally. 


\section{Control of cDC Function?}

Retinoic acid production required for Treg induction across cDC1s and cDC2s?

Klf4 required for Th2 induction across cDC2s? Notch2 required for Th17 induction across cDC2s?

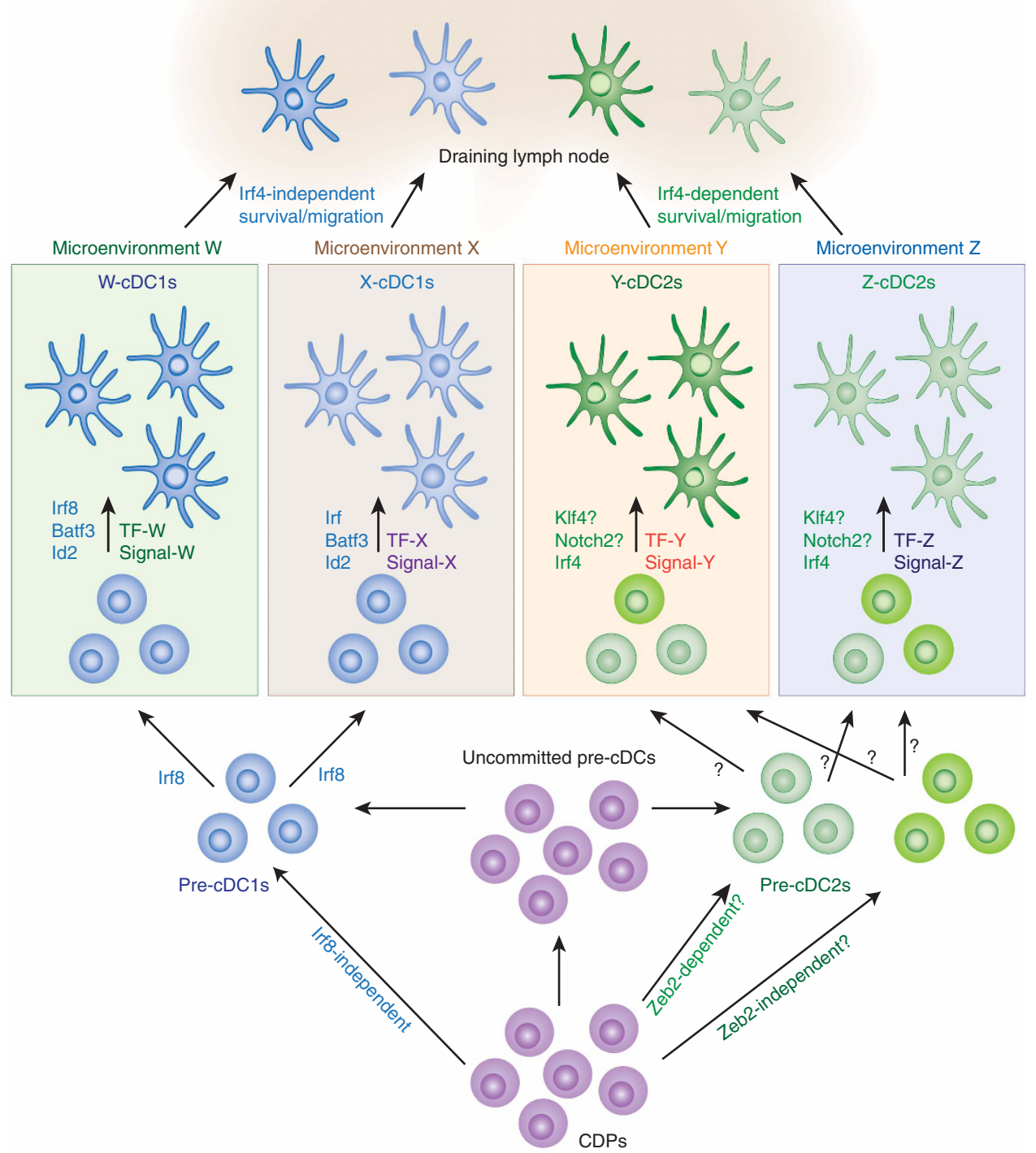

Figure 3 Proposed model for $\mathrm{CDC}$ subset development and function. One hypothesis for the presence of different cDC1 and cDC2 subsets at different tissues is that these are the result of the different microenvironments in which these DCs develop. Thus committed pre-cDC1s (which require Irf8 for their differentiation into $\mathrm{cDC} 1 \mathrm{~s}$ ) or committed pre-cDC2s (some of which require Zeb2 for their differentiation into cDC2s) enter into distinct microenvironments in any given tissue and acquire the markers, gene expression profile, and functional capacities of that given environment due to the specific signals and TFs related to that niche. These distinct subsets then migrate to their respective draining lymph nodes and induce appropriate T-cell responses. Rather than one specific steady-state DC subset already being hardwired for the induction of a given $T_{\text {Helper }}$ response (e.g., $T_{H} 1, T_{H} 2$, or $T_{H} 17$ ), we hypothesize that DCs acquire given T-cell polarization properties due to the particular (inflamed) microenvironment in which they developed. It has recently been reported that $\mathrm{T}_{\mathrm{H}} 2$ responses are abrogated in the absence of Klf4. Two models could explain these findings: (1) Klf4-dependent DCs are hardwired for $\mathrm{T}_{\mathrm{H}} 2$ induction (nature) or (2) Klf4 is required for the induction of $\mathrm{T}_{\mathrm{H}} 2$ responses by any $\mathrm{CDC} 2$ subset (nurture). For the moment, we personally favor nurture by the microenvironment over nature of the DC precursor, but this remains to be experimentally addressed. CDC, conventional dendritic cell; DC, dendritic cells; TFs, transcription factors. 


\section{CONCLUDING REMARKS}

Recent technological advances have greatly aided both our identification and understanding of the different $\mathrm{CDC}$ populations present across the body. Although it is currently accepted that $\mathrm{CDCs}$ can be divided into two main lineages (recently termed $\mathrm{cDC} 1 \mathrm{~s}$ and $\mathrm{cDC} 2 \mathrm{~s}$ ), these lineages can be further subdivided on the basis of their differential expression of a range of surface markers, which are not always conserved between tissues. However, how the different populations within each lineage arise, how they relate to each other and to those in other tissues, and which TFs govern their development, specification and/or function remain to be completely understood. We currently favor the hypothesis that these "subsets" sometimes represent developmental intermediates and sometimes represent distinct activation states linked to a different micro-anatomical location. This is currently only speculation, but recent advances in single-cell transcriptomics imply that we will soon be able to analyze the $\mathrm{CDC}$ compartment of multiple tissues in steady state and during inflammation at the single-cell level, and this should soon shed some light on a lot of the burning questions highlighted in this review and this means exciting times lay ahead for DC biology.

\section{ACKNOWLEDGMENTS}

DS is supported by a fellowship grant of FWO. BNL is supported by the University of Gent MRP program "Group-ID", European Research Council consolidator grant, Interuniversity Attraction Pole grant, and several FWO grants. MG is supported by a Marie Curie Reintegration grant, an Odysseus grant, and several FWO grants of the Flemish Government. CLS is supported by a Marie Curie Intra-European Fellowship (IEF) as part of Horizon 2020.

\section{DISCLOSURE}

The authors declared no conflict of interest.

c) 2017 Society for Mucosal Immunology

\section{REFERENCES}

1. Steinman, R.M. \& Cohn, Z.A. Identification of a novel cell type in peripheral lymphoid organs of mice: I. morphology, quantitation, tissue distribution. J. Exp. Med. 137, 1142-1162 (1973).

2. Anguille, S., Smits, E.L., Lion, E., van Tendeloo, V.F. \& Berneman, Z.N. Clinical use of dendritic cells for cancer therapy. Lancet Oncol. 15, e257-e267 (2014).

3. Inaba, K. et al. Generation of large numbers of dendritic cells from mouse bone marrow cultures supplemented with granulocyte/macrophage colony-stimulating factor. J. Exp. Med. 176, 1693-1702 (1992).

4. Sallusto, F. \& Lanzavecchia, A. Efficient presentation of soluble antigen by cultured human dendritic cells is maintained by granulocyte/macrophage colony-stimulating factor plus interleukin 4 and downregulated by tumor necrosis factor alpha. J. Exp. Med. 179, 1109-1118 (1994).

5. Guilliams, M. etal. Dendritic cells, monocytes and macrophages: a unified nomenclature based on ontogeny. Nat. Rev. Immunol. 14, 571-578 (2014).

6. Wu, X. et al. Mafb lineage tracing to distinguish macrophages from other immune lineages reveals dual identity of Langerhans cells. J. Exp. Med. 80, 2553-2565 (2016).

7. Swiecki, M. \& Colonna, M. The multifaceted biology of plasmacytoid dendritic cells. Nat. Rev. Immunol. 15, 471-485 (2015).

8. Merad, M., Sathe, P., Helft, J., Miller, J. \& Mortha, A. The dendritic cell lineage: ontogeny and function of dendritic cells and their subsets in the steady state and the inflamed setting. Annu. Rev. Immunol. 31, 563-604 (2013).
9. Banchereau, J. \& Steinman, R.M. Dendritic cells and the control of immunity. Nature 392, 245-252 (1998).

10. Bain, C.C. et al. Resident and pro-inflammatory macrophages in the colon represent alternative context-dependent fates of the same Ly6Chi monocyte precursors. Mucosal Immunol. 6, 498-510 (2013).

11. Bain, C.C. et al. Constant replenishment from circulating monocytes maintains the macrophage pool in the intestine of adult mice. Nat. Immunol. 15, 929-937 (2014).

12. Scott, C.L. et al. CCR2(+)CD103(-) intestinal dendritic cells develop from DC-committed precursors and induce interleukin-17 production by $T$ cells. Mucosal Immunol. 8, 327-339 (2014).

13. You, Q. et al. Role of hepatic resident and infiltrating macrophages in liver repair after acute injury. Biochem. Pharmacol. 86, 836-843 (2013).

14. Scott, C.L. et al. Bone marrow-derived monocytes give rise to selfrenewing and fully differentiated Kupffer cells. Nat. Commun. 7, 10321 (2016).

15. Plantinga, M. et al. Conventional and monocyte-derived CD11b(+) dendritic cells initiate and maintain T helper 2 cell-mediated immunity to house dust mite allergen. Immunity 38, 322-335 (2013).

16. Guilliams, M. et al. Alveolar macrophages develop from fetal monocytes that differentiate into long-lived cells in the first week of life via GM-CSF. J. Exp. Med. 210, 1977-1992 (2013).

17. Molawi, K. et al. Progressive replacement of embryo-derived cardiac macrophages with age. J. Exp. Med. 211, 2151-2158 (2014).

18. Epelman, S. et al. Embryonic and adult-derived resident cardiac macrophages are maintained through distinct mechanisms at steady state and during inflammation. Immunity 40, 91-104 (2014).

19. Caton, M.L., Smith-Raska, M.R. \& Reizis, B. Notch-RBP-J signaling controls the homeostasis of CD8- dendritic cells in the spleen. J. Exp. Med. 204, 1653-1664 (2007).

20. Postigo, A.A., Corbí, A.L., Sánchez-Madrid, F. \& de Landázuri, M.O. Regulated expression and function of CD11C/CD18 integrin on human B lymphocytes. Relation between attachment to fibrinogen and triggering of proliferation through CD11c/CD18. J. Exp. Med. 174, 1313-1322 (1991).

21. Satpathy, A.T. et al. Zbtb46 expression distinguishes classical dendritic cells and their committed progenitors from other immune lineages. J. Exp. Med. 209, 1135-1152 (2012).

22. Meredith, M.M. et al. Expression of the zinc finger transcription factor zDC (Zbtb46, Btbd4) defines the classical dendritic cell lineage. J. Exp. Med. 209, 1153-1165 (2012).

23. Briseño, C.G. et al. Distinct transcriptional programs control crosspriming in classical and monocyte-derived dendritic cells. Cell Rep. 15, 2462-2474 (2016).

24. Loschko, J. et al. Inducible targeting of CDCs and their subsets in vivo. J. Immunol. Methods 434, 32-38 (2016).

25. Miller, J.C. et al. Deciphering the transcriptional network of the dendritic cell lineage. Nat. Immunol. 13, 888-899 (2012).

26. Gautier, E.L. et al. Gene-expression profiles and transcriptional regulatory pathways that underlie the identity and diversity of mouse tissue macrophages. Nat. Immunol. 13, 1118-1128 (2012).

27. Langlet, C. et al. CD64 expression distinguishes monocyte-derived and conventional dendritic cells and reveals their distinct role during intramuscular immunization. J. Immunol. 188, 1751-1760 (2012).

28. Tamoutounour, S. et al. CD64 distinguishes macrophages from dendritic cells in the gut and reveals the Th1-inducing role of mesenteric lymph node macrophages during colitis. Eur. J. Immunol. 42, 3150-3166 (2012).

29. Guilliams, M. \& van de Laar, L. A Hitchhiker's guide to myeloid cell subsets: practical implementation of a novel mononuclear phagocyte classification system. Front. Immunol. 6, 651 (2015).

30. Guilliams, M. et al. Unsupervised high-dimensional analysis aligns dendritic cells across tissues and species. Immunity 45, 669-684 (2016).

31. Hildner, K. et al. Batf3 deficiency reveals a critical role for CD $8 \alpha+$ dendritic cells in cytotoxic T cell immunity. Science 322, 1097-1100 (2008).

32. Grajales-Reyes, G.E. et al. Batf3 maintains autoactivation of Irf8 for commitment of a $\operatorname{CD} 8 \alpha(+)$ conventional DC clonogenic progenitor. Nat. Immunol. 16, 708-717 (2015).

33. Sichien, D. et al. IRF8 transcription factor controls survival and function of terminally differentiated conventional and plasmacytoid dendritic cells, respectively. Immunity 45, 626-640 (2016). 
34. Ginhoux, F. et al. The origin and development of nonlymphoid tissue CD103 + DCs. J. Exp. Med. 206, 3115-3130 (2009).

35. Schlitzer, A. et al. IRF4 transcription factor-dependent CD11b(+) dendritic cells in human and mouse control mucosal IL-17 cytokine responses. Immunity 38, 970-983 (2013).

36. Persson, E.K. et al. IRF4 transcription-factor-dependent CD103(+) $\mathrm{CD} 11 \mathrm{~b}(+)$ dendritic cells drive mucosal T Helper 17 cell differentiation. Immunity 38, 958-969 (2013).

37. Bajaña, S., Turner, S., Paul, J., Ainsua-Enrich, E. \& Kovats, S. IRF4 and IRF8 act in CD11c + cells to regulate terminal differentiation of lung tissue dendritic cell. J. Immunol. 196, 1666-1677 (2016).

38. Bajaña, S., Roach, K., Turner, S., Paul, J. \& Kovats, S. IRF4 promotes cutaneous dendritic cell migration to lymph nodes during homeostasis and inflammation. J. Immunol. 189, 3368-3377 (2012).

39. Crozat, K. et al. Cutting edge: expression of XCR1 defines mouse lymphoid-tissue resident and migratory dendritic cells of the CD8 $\alpha+$ type. J. Immunol. 187, 4411-4415 (2011).

40. Bachem, A. et al. Expression of XCR1 characterizes the Batf3-dependent lineage of dendritic cells capable of antigen cross-presentation. Front. Immunol. 3, 214 (2012).

41. Gurka, S., Hartung, E., Becker, M. \& Kroczek, R.A. Mouse conventional dendritic cells can be universally classified based on the mutually exclusive expression of XCR1 and SIRP $\alpha$. Front. Immunol. 6, 35 (2015).

42. Bimczok, D., Sowa, E.N., Faber-Zuschratter, H., Pabst, R. \& Rothkötter, H.-J. Site-specific expression of CD11b and SIRPalpha (CD172a) on dendritic cells: implications for their migration patterns in the gut immune system. Eur. J. Immunol. 35, 1418-1427 (2005).

43. Saito, Y. et al. Regulation by $\operatorname{SIRP} \alpha$ of dendritic cell homeostasis in lymphoid tissues. Blood 116, 3517-3525 (2010).

44. Lewis, K.L. et al. Notch2 receptor signaling controls functional differentiation of dendritic cells in the spleen and intestine. Immunity 35, 780-791 (2011).

45. Cerovic, V. et al. Lymph borne CD8a + DCs are uniquely able to crossprime CD8 + Tcells with antigen acquired from intestinal epithelial cells. Mucosal Immunol. 8, 38-48 (2014).

46. Poulin, L.F. et al. Characterization of human DNGR-1+ BDCA3+ leukocytes as putative equivalents of mouse CD8alpha + dendritic cells. J. Exp. Med. 207, 1261-1271 (2010).

47. Manz, M.G., Traver, D., Miyamoto, T., Weissman, I.L. \& Akashi, K. Dendritic cell potentials of early lymphoid and myeloid progenitors. Blood 97, 3333-3341 (2001).

48. Akashi, K., Traver, D., Miyamoto, T. \& Weissman, I.L. A clonogenic common myeloid progenitor that gives rise to all myeloid lineages. Nature 404, 193-197 (2000).

49. Wu, L. et al. Development of thymic and splenic dendritic cell populations from different hemopoietic precursors. Blood 98, 3376-3382 (2001).

50. Auffray, C. et al. CX3CR1 + CD115 + CD135 + common macrophage/ $\mathrm{DC}$ precursors and the role of $\mathrm{CX} 3 \mathrm{CR} 1$ in their response to inflammation. J. Exp. Med. 206, 595-606 (2009).

51. Fogg, D.K. et al. A clonogenic bone marrow progenitor specific for macrophages and dendritic cells. Science 311, 83-87 (2006).

52. Waskow, C. et al. The receptor tyrosine kinase Flt 3 is required for dendritic cell development in peripheral lymphoid tissues. Nat. Immunol. 9, 676-683 (2008).

53. Hettinger, J. et al. Origin of monocytes and macrophages in a committed progenitor. Nat. Immunol. 14, 821-830 (2013).

54. Naik, S.H. et al. Development of plasmacytoid and conventional dendritic cell subtypes from single precursor cells derived in vitro and in vivo. Nat. Immunol. 8, 1217-1226 (2007).

55. Onai, N. et al. A clonogenic progenitor with prominent plasmacytoid dendritic cell developmental potential. Immunity 38, 943-957 (2013).

56. Onai, N. et al. Identification of clonogenic common Flt3 + M-CSFR + plasmacytoid and conventional dendritic cell progenitors in mouse bone marrow. Nat. Immunol. 8, 1207-1216 (2007).

57. Sathe, P. et al. Lymphoid tissue and plasmacytoid dendritic cells and macrophages do not share a common macrophage-dendritic cellrestricted progenitor. Immunity 41, 104-115 (2014).

58. Onai, N. \& Ohteki, T. Bipotent or oligopotent? A macrophage and DC progenitor revisited. Immunity 41, 5-7 (2014).
59. D'Amico, A. \& Wu, L. The early progenitors of mouse dendritic cells and plasmacytoid predendritic cells are within the bone marrow hemopoietic precursors expressing Flt3. J. Exp. Med. 198, 293-303 (2003).

60. Diao, J. et al. In situ replication of immediate dendritic cell (DC) precursors contributes to conventional DC homeostasis in lymphoid tissue. J. Immunol. 176, 7196-7206 (2006).

61. Naik, S.H. et al. Intrasplenic steady-state dendritic cell precursors that are distinct from monocytes. Nat. Immunol. 7, 663-671 (2006).

62. Schlitzer, A. et al. Identification of CDC1- and cDC2-committed DC progenitors reveals early lineage priming at the common DC progenitor stage in the bone marrow. Nat. Immunol. 16, 718-728 (2015).

63. Naik, S.H. et al. Diverse and heritable lineage imprinting of early haematopoietic progenitors. Nature 496, 229-232 (2013).

64. Breton, G. et al. Circulating precursors of human CD1C + and CD141 + dendritic cells. J. Exp. Med. 212, 401-413 (2015).

65. Lee, J. et al. Restricted dendritic cell and monocyte progenitors in human cord blood and bone marrow. J. Exp. Med. 212, 385-399 (2015).

66. Schmid, M.A., Kingston, D., Boddupalli, S. \& Manz, M.G. Instructive cytokine signals in dendritic cell lineage commitment. Immunol. Rev. 234, 32-44 (2010).

67. Laouar, Y., Welte, T., Fu, X.-Y. \& Flavell, R.A. STAT3 is required for Flt3Ldependent dendritic cell differentiation. Immunity 19, 903-912 (2003).

68. Sathaliyawala, T. et al. Mammalian target of rapamycin controls dendritic cell development downstream of Flt3 ligand signaling. Immunity 33, 597-606 (2010).

69. Maraskovsky, E. et al. Dramatic increase in the numbers of functionally mature dendritic cells in Flt3 ligand-treated mice: multiple dendritic cell subpopulations identified. J. Exp. Med. 184, 1953-1962 (1996).

70. McKenna, H.J. et al. Mice lacking flt3 ligand have deficient hematopoiesis affecting hematopoietic progenitor cells, dendritic cells, and natural killer cells. Blood 95, 3489-3497 (2000).

71. Salmon, H. et al. Expansion and activation of CD103(+) dendritic cell progenitors at the tumor site enhances tumor responses to therapeutic PD-L1 and BRAF inhibition. Immunity 44, 924-938 (2016).

72. Onai, N., Obata-Onai, A., Tussiwand, R., Lanzavecchia, A. \& Manz, M.G. Activation of the Flt3 signal transduction cascade rescues and enhances type I interferon-producing and dendritic cell development. J. Exp. Med. 203, 227-238 (2006).

73. Greter, M. et al. GM-CSF controls nonlymphoid tissue dendritic cell homeostasis but is dispensable for the differentiation of inflammatory dendritic cells. Immunity 36, 1031-1046 (2012).

74. King, I.L., Kroenke, M.A. \& Segal, B.M. GM-CSF-dependent, CD103+ dermal dendritic cells play a critical role in Th effector cell differentiation after subcutaneous immunization. J. Exp. Med. 207, 953-961 (2010).

75. Bogunovic, M. et al. Origin of the lamina propria dendritic cell network. Immunity 31, 513-525 (2009).

76. Edelson, B.T. et al. Batf3-dependent CD11b(low/-) peripheral dendritic cells are GM-CSF-independent and are not required for Th cell priming after subcutaneous immunization. PLOS ONE 6, e25660 (2011).

77. Kabashima, K. et al. Intrinsic lymphotoxin-beta receptor requirement for homeostasis of lymphoid tissue dendritic cells. Immunity 22, 439-450 (2005).

78. MacDonald, K.P.A. et al. The colony-stimulating factor 1 receptor is expressed on dendritic cells during differentiation and regulates their expansion. J. Immunol. 175, 1399-1405 (2005).

79. Fancke, B., Suter, M., Hochrein, H. \& O'Keeffe, M. M-CSF: a novel plasmacytoid and conventional dendritic cell poietin. Blood 111, 150-159 (2008).

80. Murphy, K.M. Transcriptional control of dendritic cell development. Adv. Immunol. 120, 239-267 (2013).

81. Seillet, C. \& Belz, G.T. Terminal differentiation of dendritic cells. Adv. Immunol. 120, 185-210 (2013).

82. Durai, V. \& Murphy, K.M. Functions of murine dendritic cells. Immunity 45, 719-736 (2016).

83. Schiavoni, G. et al. ICSBP is essential for the development of mouse type I interferon-producing cells and for the generation and activation of CD8alpha(+) dendritic cells. J. Exp. Med. 196, 1415-1425 (2002).

84. Kurotaki, D. et al. IRF8 inhibits $\mathrm{C} / \mathrm{EBP} \alpha$ activity to restrain mononuclear phagocyte progenitors from differentiating into neutrophils. Nat. Commun. 5, 4978 (2014). 
85. Yáñez, A., Ng, M.Y., Hassanzadeh-Kiabi, N. \& Goodridge, H.S. IRF8 acts in lineage-committed rather than oligopotent progenitors to control neutrophil vs monocyte production. Blood 125, 1452-1459 (2015).

86. Becker, A.M. et al. IRF-8 extinguishes neutrophil production and promotes dendritic cell lineage commitment in both myeloid and lymphoid mouse progenitors. Blood 119, 2003-2012 (2012).

87. Luda, K.M. et al. IRF8 transcription-factor-dependent classical dendritic cells are essential for intestinal T cell homeostasis. Immunity 44, 860-874 (2016).

88. Carotta, S. et al. The transcription factor PU.1 controls dendritic cell development and Flt3 cytokine receptor expression in a dose-dependent manner. Immunity 32, 628-641 (2010).

89. Rathinam, C. et al. The transcriptional repressor Gfi1 controls STAT3-dependent dendritic cell development and function. Immunity 22, 717-728 (2005).

90. Jackson, J.T. et al. Id2 expression delineates differential checkpoints in the genetic program of CD $8 \alpha+$ and CD103 + dendritic cell lineages. EMBO J. 30, 2690-2704 (2011).

91. Kashiwada, M., Pham, N.-L. L., Pewe, L.L., Harty, J.T. \& Rothman, P.B. NFIL3/E4BP4 is a key transcription factor for CD8 $\alpha$ dendritic cell development. Blood 117, 6193-6197 (2011).

92. Tussiwand, R. et al. Compensatory dendritic cell development mediated by BATF-IRF interactions. Nature 490, 502-507 (2012).

93. Tailor, P., Tamura, T., Morse, H.C. \& Ozato, K. The BXH2 mutation in IRF8 differentially impairs dendritic cell subset development in the mouse. Blood 111, 1942-1945 (2008).

94. Satpathy, A.T. et al. Notch2-dependent classical dendritic cells orchestrate intestinal immunity to attaching-and-effacing bacterial pathogens. Nat. Immunol. 14, 937-948 (2013).

95. Tussiwand, R. et al. Klf4 expression in conventional dendritic cells is required for T helper 2 cell responses. Immunity 42, 916-928 (2015).

96. Williams, J.W. et al. Transcription factor IRF4 drives dendritic cells to promote Th2 differentiation. Nat. Commun. 4, 2990 (2013).

97. Gao, Y. et al. Control of Thelper 2 responses by transcription factor IRF4dependent dendritic cells. Immunity 39, 722-732 (2013).

98. Kumamoto, $Y$. et al. CD301b dermal dendritic cells drive $T$ helper 2 cell-mediated immunity. Immunity 39, 733-743 (2013).

99. Zhou, Q. et al. GM-CSF-licensed CD11b + lung dendritic cells orchestrate Th2 immunity to Blomia tropicalis. J. Immunol. 193, 496-509 (2014).

100. Scott, C.L. et al. The transcription factor Zeb2 regulates development of conventional and plasmacytoid DCs by repressing Id2. J. Exp. Med. 213, 897-911 (2016).

101. $\mathrm{Wu}, \mathrm{X}$. et al. Transcription factor Zeb2 regulates commitment to plasmacytoid dendritic cell and monocyte fate. Proc. Natl. Acad. Sci. USA 113, 14775-14780 (2016).

102. Mowat, A.M. Anatomical basis of tolerance and immunity to intestinal antigens. Nat. Rev. Immunol. 3, 331-341 (2003).

103. Schraml, B.U. et al. Genetic tracing via DNGR-1 expression history defines dendritic cells as a hematopoietic lineage. Cell 154, 843-858 (2013).

104. Cerovic, V. et al. Intestinal CD103(-) dendritic cells migrate in lymph and prime effector T cells. Mucosal Immunol. 6, 104-113 (2013).

105. Persson, E.K., Scott, C.L., Mowat, A.M. \& Agace, W.W. Dendritic cell subsets in the intestinal lamina propria: ontogeny and function. Eur. J. Immunol. 43, 3098-3107 (2013).

106. Houston, S.A. et al. The lymph nodes draining the small intestine and colon are anatomically separate and immunologically distinct. Mucosal Immunol. 9, 468-478 (2016).

107. Denning, T.L. et al. Functional specializations of intestinal dendritic cell and macrophage subsets that control Th17 and regulatory T cell responses are dependent on the T cell/APC ratio, source of mouse strain, and regional localization. J. Immunol. 187, 733-747 (2011).

108. Mowat, A.M. \& Agace, W.W. Regional specialization within the intestinal immune system. Nat. Rev. Immunol. 14, 667-685 (2014).

109. Lee, H. et al. Phenotype and function of nasal dendritic cells. Mucosal Immunol. 8, 1083-1098 (2015).

110. Scott, C.L., Murray, T. F. P. Z., Beckham, K.S.H., Douce, G. \& Mowat, A.M. Signal regulatory protein alpha $(\mathrm{SIRP} \alpha)$ regulates the homeostasis of CD103(+) CD11b(+) DCs in the intestinal lamina propria. Eur. J. Immunol. 44, 3658-3668 (2014).

111. Watchmaker, P.B. et al. Comparative transcriptional and functional profiling defines conserved programs of intestinal DC differentiation in humans and mice. Nat. Immunol. 15, 98-108 (2014).

112. Sung, S.-S. J. et al. A major lung CD103 (alphaE)-beta7 integrin-positive epithelial dendritic cell population expressing Langerin and tight junction proteins. J. Immunol. 176, 2161-2172 (2006).

113. Hovav, A.-H. Dendritic cells of the oral mucosa. Mucosal Immunol. 7 , 27-37 (2013).

114. Flacher, V. et al. Expression of langerin/CD207 reveals dendritic cell heterogeneity between inbred mouse strains. Immunology 123, 339-347 (2008).

115. Bigley, V. et al. Langerin-expressing dendritic cells in human tissues are related to CD1c + dendritic cells and distinct from Langerhans cells and CD141high XCR1 + dendritic cells. J. Leukoc. Biol. 97, 627-634 (2015).

116. Haniffa, M. et al. Human tissues contain CD141hi cross-presenting dendritic cells with functional homology to mouse CD103 + nonlymphoid dendritic cells. Immunity 37, 60-73 (2012).

117. Maisonnasse, P. et al. The respiratory DC/macrophage network at steady-state and upon influenza infection in the swine biomedical model. Mucosal Immunol. 9, 835-849 (2016).

118. Martínez-Cingolani, C. et al. Human blood BDCA-1 dendritic cells differentiate into Langerhans-like cells with thymic stromal lymphopoietin and TGF- $\beta$. Blood 124, 2411-2420 (2014).

119. Takahara, K. et al. Identification and expression of mouse Langerin (CD207) in dendritic cells. Int. Immunol. 14, 433-444 (2002).

120. Valladeau, J. et al. Identification of mouse langerin/CD207 in Langerhans cells and some dendritic cells of lymphoid tissues. J. Immunol. 168, 782-792 (2002).

121. Demedts, I.K., Brusselle, G.G., Vermaelen, K.Y. \& Pauwels, R.A. Identification and characterization of human pulmonary dendritic cells. Am. J. Respir. Cell Mol. Biol. 32, 177-184 (2005).

122. Malissen, B., Tamoutounour, S. \& Henri, S. The origins and functions of dendritic cells and macrophages in the skin. Nat. Rev. Immunol. 14, 417-428 (2014).

123. Guilliams, M. et al. Skin-draining lymph nodes contain dermis-derived CD103(-) dendritic cells that constitutively produce retinoic acid and induce Foxp3(+) regulatory T cells. Blood 115, 1958-1968 (2010).

124. Gao, Y. et al. TLR2 directing PD-L2 expression inhibit T cells response in Schistosoma japonicum infection. PLoS ONE 8, e82480 (2013).

125. Hoeffel, G. et al. Adult Langerhans cells derive predominantly from embryonic fetal liver monocytes with a minor contribution of yolk sac-derived macrophages. J. Exp. Med. 209, 1167-1181 (2012).

126. Ginhoux, F. \& Jung, S. Monocytes and macrophages: developmental pathways and tissue homeostasis. Nat. Rev. Immunol. 14, 392-404 (2014).

127. Poulin, L.F. et al. The dermis contains langerin + dendritic cells that develop and function independently of epidermal Langerhans cells. J. Exp. Med. 204, 3119-3131 (2007).

128. Ginhoux, F. et al. Blood-derived dermal langerin + dendritic cells survey the skin in the steady state. J. Exp. Med. 204, 3133-3146 (2007).

129. Henri, S. et al. CD207 + CD103 + dermal dendritic cells cross-present keratinocyte-derived antigens irrespective of the presence of Langerhans cells. J. Exp. Med. 207, 189-206 (2010).

130. Capucha, T. et al. Distinct murine mucosal Langerhans cell subsets develop from pre-dendritic cells and monocytes. Immunity 43, 369-381 (2015).

131. Zeng, R. et al. Retinoic acid regulates the development of a gut-homing precursor for intestinal dendritic cells. Mucosal Immunol. 6, 847-856 (2012).

132. Guilliams, M., Lambrecht, B.N. \& Hammad, H. Division of labor between lung dendritic cells and macrophages in the defense against pulmonary infections. Mucosal Immunol. 6, 464-473 (2013).

133. Edelson, B.T. et al. Peripheral CD103 + dendritic cells form a unified subset developmentally related to CD8alpha + conventional dendritic cells. J. Exp. Med. 207, 823-836 (2010).

134. Tamoutounour, S. et al. Origins and functional specialization of macrophages and of conventional and monocyte-derived dendritic cells in mouse skin. Immunity 39, 925-938 (2013). 